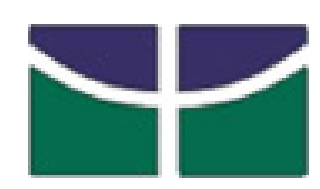

UNIVERSIDADE DE BRASÍLIA - UnB

Centro de Excelência em Turismo

\title{
A IMPORTÂNCIA DA IMAGEM NO PROCESSO \\ DE ESCOLHA DA DESTINAÇÃO TURÍSTICA
}

Jun Matsuoka Tomikawa

Brasília (DF), março de 2004. 
UNIVERSIDADE DE BRASÍLIA - UnB

Centro de Excelência em Turismo

Curso de Especialização em Gestão e Marketing do Turismo V

\title{
A IMPORTÂNCIA DA IMAGEM NO PROCESSO \\ DE ESCOLHA DA DESTINAÇÃO TURÍSTICA
}

\author{
Autor \\ Jun Matsuoka Tomikawa \\ Orientador \\ Prof. Carlos Rodrigues, Msc \\ Avaliador \\ Domingos Sávio Spezia, Msc
}

Monografia apresentada ao Centro de Excelência em Turismo da UnB, como requisito para obtenção do título de Especialista em Turismo.

Brasília (DF), março de 2004. 


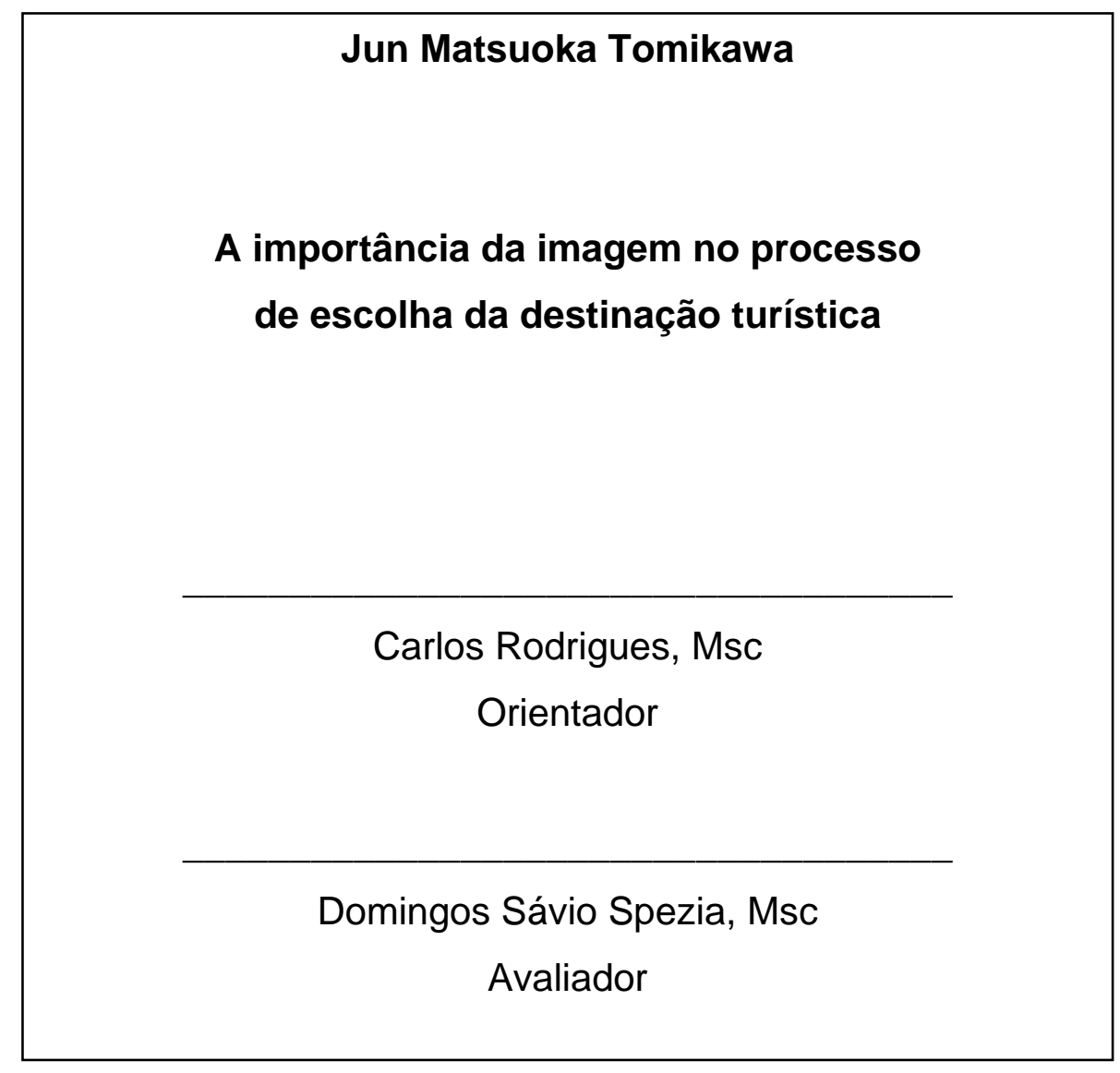




\section{Dedicatória}

Dedico este trabalho aos meus pais, Kenji e Elza. 


\section{Agradecimentos}

Agradeço:

À minha família (pai, mãe e Mari) razão da minha vida;

Aos amigos: Cocota, Paulo Enio, Rafael, Rodrigo e Tomás (Varejas) por me acompanharem por todos esses anos; Sonoda, Yakko, Dani, Mari Mari, Marta, Ane e, em especial, Lu, por ter me ajudado nas traduções e em todos os momentos em que precisei extra monografia; Paty, Klaudia, Alberto, Fê, Dani, Sandra e Eugenia por terem dividido seus conhecimentos em turismo comigo; e Aline, porque todo artista precisa de uma musa inspiradora;

Aos mestres, Carlos Rodrigues, pelos ensinamentos em sala de aula e durante a execução deste trabalho, e Sérgio Leal que, mesmo não me conhecendo pessoalmente, dispôs de seu tempo para me ajudar;

À Internet, pois sem ela, eu não teria encontrado o professor Sérgio e a comunicação com o professor Carlos não teria sido tão eficiente;

A Deus. 


\section{Epígrafe}

"Começar já é metade de toda ação".

(Provérbio grego) 


\section{Resumo}

O desenvolvimento crescente da indústria turística e o conseqüente aumento da competitividade entre as destinações tornam necessária a busca pela diferenciação. Nessa busca, até mesmo a iniciativa privada, mas principalmente os órgãos públicos do turismo brasileiro investem em fatores primordiais como infra-estrutura, mas não reconhecem um dos mais importantes aspectos na escolha da destinação: sua imagem. Prova disso é a falta de estudos sobre o assunto no Brasil. Portanto, esse trabalho busca a compreensão do que é imagem de uma destinação, o processo de decisão do turista, a importância da imagem, como ela é formada e como ela pode ser medida. 


\begin{abstract}
The increasing tourist industry development and the consequent competitiveness increase among the destinations make the efforts to differentiation necessary. In this search, both private initiative, but mainly Brazilian tourism public agencies invest in primordial factors such as infra-structure, but they do not recognize one of the most important aspects in the destination choice: its image. The lack of studies on the subject in Brazil attests this fact. Therefore, this work looks at the understanding of the destination image concepts, the tourist decision process, image importance, how it is formed and as how it can be measured.
\end{abstract}




\section{Sumário}

INTRODUÇÃO

1 - O PROCESSO DE ESCOLHA DA DESTINAÇÃO TURÍSTICA

1.1 - Os fundamentos do comportamento do consumidor e o turismo

1.2 - Energizadores e Efetivadores de demanda

1.2.1 - Motivação

1.2.2 - A hierarquia das necessidades de Maslow 19

1.2.3 - Motivação em Turismo 21

1.3 - Os papéis e o processo de tomada de decisões no turismo. 22

1.3.1 - Tipologias de turistas 22

1.3.2 - O papel e a influência da família 24

1.3.3 - A importância da imagem 24

1.4 - Determinantes da demanda turística 25

1.4.1 - Estilo de vida 25

1.4.2 - Ciclo da vida 26

1.5 - Demanda turística reprimida 27

1.6 - Modelos da demanda turística 28

1.6.1 - Wahab, Crampon e Rothfield (1976) 29

1.6.2 - Schmoll (1977) 30

1.6.3 - Mayo e Jarvis (1981) 32

1.6.4 - Mathieson e Wall (1982) 32

1.6.5 - Woodside e Lysonski (1989) 34

1.6.6 - Um e Crompton (1990) 35

1.6.7 - Moscardo et al. (1996) 36 
2.1 - O que são imagens de destinações turísticas? 38

2.2 - A formação da imagem 40

2.3 - Componentes de Imagem 43

2.4 - Determinantes de imagem 46

2.5 - Mensuração da imagem de destinações 48

2.5.1 - A fase qualitativa: a descoberta das construções 52

2.5.2 - A fase quantitativa: mensuração da imagem 53

3 - A IMAGEM DO BRASIL NO EXTERIOR 54

3.1 - Confederação Nacional do Transporte 54

3.2 - Purdue University 55

4 - ANÁLISES DOS DADOS

5 - CONCLUSÕES $\quad 64$

$\begin{array}{ll}\text { REFERÊNCIAS BIBLIOGRÁFICAS } & 67\end{array}$ 


\section{Lista de Ilustrações}

- Figura 1.1 Modelo de estímulo e resposta (Kotler, 2002)

- Figura 1.2 Processo de decisão do consumidor em turismo (Cooper et al, 2001)

- Figura 1.3 Hierarquia das necessidades (Adaptação de Maslow, 1943)

- Figura 1.4 Classificação de turistas de Cohen (Boniface and Cooper, 1987; adaptado de Cohen, 1972; em Cooper et al, 2001)

- Figura 1.5 Categorias de Valores e Estilo de Vida (Cooper et al, 2001, adaptado de Shih, 1986)

- Figura 1.6 Idade doméstica e demanda turística (Adaptado de Cooper et al, 2001)

- Figura 1.7 Modelo de comportamento do consumidor (Cooper et al, 2001, adaptado de Wahab, Crampton e Rothfield, 1976)

- Figura 1.8 Modelo de Schmoll (Cooper et al, 2001, adaptado de Schmoll, 1977)

- Figura 1.9 Comportamento na compra de viagens (Cooper et al, 2001, adaptado de Mathieson e Wall, 1982)

- Figura 1.10 Modelo de Mathieson e Wall (Cooper et al, 2001, adaptado de Mathieson e Wall, 1982)

- Figura 1.11 Modelo de escolha de destinação baseada em atividades (Cooper et al, 2001, adaptado de Moscardo et al, 1996) 
- Figura 2.1 Fatores de influência na formação da imagem turística pelos consumidores (Stabler, 1988)

- Figura 2.2 Teoria dos estágios da imagem da destinação (Gunn, 1972, p. 120)

- Figura 2.3 Componentes da imagem de destinações (Echtner e Ritchie, 1991)

- Figura 2.4 Determinantes de imagem (adaptado de Keller, 2000) 46

- Figura 2.5 Métodos utilizados na pesquisa de imagem das destinações: Estruturados x Não-estruturados (Jenkins, 1999)

- Figura 2.6 Um modelo para a pesquisa de imagem das destinações (Jenkins , 1999) 


\section{Introdução}

A indústria do turismo é uma das mais promissoras do século $\mathrm{XXI}$. O desenvolvimento dessa atividade em âmbito mundial torna o ambiente turístico cada vez mais competitivo, em que a disputa pelo mercado consumidor fica mais acirrada entre as regiões, as destinações turísticas.

Sempre foi dito que o Brasil é um país com enorme potencial turístico. Tanto que o governo lançou o Plano Nacional do Turismo (PNT) em 2003 com metas bastante ousadas: aumentar para 9 milhões o número de turistas estrangeiros no Brasil, gerando US\$ 8 bilhões em divisas.

Pode-se dizer que o governo está muito otimista, pois, segundo dados da OMT (Organização Mundial do Turismo) de 2002, o Brasil é apenas o $34^{\circ}$ país do mundo em turismo receptivo, recebendo aproximadamente 3,8 milhões de turistas, número $20 \%$ menor que o de 2001. Ou seja, o número de turistas estrangeiros que visitam o Brasil anualmente está muito aquém da meta estabelecida. $E$ o que fazem os órgãos públicos municipais, estaduais e federais para reverter essa situação?

Para criar diferenciais competitivos, a maioria das destinações apela para fatores primordiais como localização, infra-estrutura básica e turística e atrativos. No entanto, um fator importante para a escolha de uma destinação não vem sendo reconhecido nem estudado: a sua imagem.

Prova disso é o número de trabalhos sobre o assunto publicados no Brasil. Em seu artigo A relevância da imagem para o processo de escolha de destinações, Leal (2002) identificou apenas dois trabalhos sobre o tema (Santana, 2001; Bignami, 2002) que são muito recentes. Já no exterior, os primeiros trabalhos sobre o assunto datam da década de 70 .

Na conferência da Travel and Tourism Research Association (TTRA) de 2000 em Los Angeles, John Hunt fez uma analogia de três camponeses desbravando um novo campo para descrever as pesquisas sobre imagem de destinações nos anos 
70 conduzidas por ele mesmo, Edward Mayo e Clare Gunn. Hoje, o assunto tornouse um dos mais predominantes na literatura turística internacional.

Steve Pike (2002) pesquisou toda produção científica internacional sobre a análise da imagem da destinação de 1973 a 2000 e encontrou 142 estudos sobre o assunto,

Suas principais descobertas foram:

- Relativamente poucos estudos tentaram medir a imagem da destinação por um contexto de viagem específico (apenas 23 dos 142);

- A região mais estudada foi a América do Norte com 58 estudos, seguida da Europa (45), Ásia (25), Oceania (19), África (14), América Central/Caribe (9), Pacífico Sul (5) e América do Sul (1);

- Mais da metade desses estudos (75) mediu a percepção de apenas uma destinação isoladamente, sem a comparação com outras destinações concorrentes;

- O tipo de destinação mais avaliado foram os países, com 56 estudos, seguidos de estados (27), cidades (26), resorts (23) e regiões (11);

- A grande maioria dos estudos usou métodos estruturados para operacionalizar a construção da imagem da destinação;

- Menos da metade dos estudos (63) utilizou algum método qualitativo, envolvendo consumidores, em algum estágio da pesquisa;

- A técnica de análise de dados mais popular foi a análise de fatores, relatada em 41 estudos, seguida de t-tests (21), mapeamento de percepção (21), análise de significados (20), análise de clusters (14), análise de importânciadesempenho (9), lista de repertório (8), técnicas de mapeamento (3), cálculo permanente (2) e análises associadas (1). 
- 59 estudos tiveram como público-alvo os visitantes da destinação, enquanto 55 incluíram os consumidores turísticos no seu local de residência. Esse último público é importante, pois permite a captação de visitantes em potencial e não-visitantes. Outros estudos procuraram a visão de trade turístico/experts (20), estudantes (15), profissionais de organizações turísticas da destinação (3) e comunidade local (2);

- Os estudos abrangeram um grande grupo de interesses como: o efeito na visitação (15), segmentação (12), diferenças de imagem entre diferentes grupos (8), afeição (6), o efeito da distância em relação à destinação (6), intermediários (6), imagem induzida (6), top of mind (maior lembrança)/parâmetros de decisão (5), cultura (4), mudança de imagem com o passar do tempo (3), imagens negativas (3), o efeito de familiaridade com a destinação (3), destinações menos desenvolvidas (3), duração da estadia (3), impacto de um acontecimento (2), validade de uma escala (2), valor (2), formação da imagem (2) e estudos únicos sobre a imagem primária/básica, turismo rural, clima, confiança do viajante, decisões por impulso, contexto de viagem, barreiras de posicionamento, fotografias pessoais de férias, motivação, experiência, estereótipos, orçamento de viagem, intenção de visita e políticas de organizações de marketing das destinações.

Observa-se, como já foi citado anteriormente, a carência de estudos sobre o assunto imagem de destinações no Brasil e na América do Sul em geral. Apenas 1 trabalho estudando a imagem da América do Sul foi realizado de 1973 a 2000, segundo o levantamento de Pike.

Então, Qual a importância da imagem na escolha da destinação? Como ela é formada? Quais são seus componentes ou dimensões? É possível medi-la?

Com o objetivo de responder a essas perguntas, foi realizada uma investigação teórica-documental sobre o assunto imagem de destinações, envolvendo as motivações do consumidor no processo de escolha da destinação turística. 
Durante a investigação foram consultados obras e artigos de autores brasileiros e, principalmente, estrangeiros, no idioma original, já que o assunto ainda não recebeu em nosso país o merecido destaque, tanto em obras quanto em traduções.

As principais fontes de pesquisa foram:

- Livros;

- Periódicos;

- Internet;

- Relatórios de Órgãos Governamentais (Embratur, Ministério do Turismo);

- Pesquisa de Observação;

- Monografias e outros trabalhos acadêmicos.

Visando a um melhor entendimento, o trabalho foi dividido em 5 tópicos, apresentados abaixo:

1. Inicialmente, tentou-se compreender o comportamento do consumidor e seu processo de decisão de compra no turismo.

2. Identificadas as motivações, passou-se a estudar a formação da imagem e a sua importância para o consumidor, para, então, associá-la ao turismo e às destinações.

3. O passo seguinte foi a busca por pesquisas e documentos que indicassem a imagem do Brasil no turismo. Essa fase pode ser chamada de diagnóstico.

4. A quarta fase foi a análise dos documentos encontrados e a identificação dos fatores que levaram à formação dessa imagem e as conseqüências dela.

5. A última fase foi a de conclusão e recomendações. 
Muitos afirmam que a imagem do Brasil no exterior é negativa, mas qual a verdadeira imagem de nosso país? E se for realmente negativa, o que fazer para mudá-la?

A carência de obras sobre imagem de destinações no Brasil e a busca pela resposta dessas perguntas levaram ao interesse pelo tema. É justamente responder a essas perguntas a delimitação deste trabalho, que não tem a pretensão de ser uma obra definitiva sobre o assunto, mas sim despertar interesse que gere discussões cada vez mais profundas que contribuam para o desenvolvimento turístico brasileiro. 


\section{1 - O PROCESSO DE ESCOLHA DA DESTINAÇÃO TURÍSTICA}

O estudo dos processos de decisão do consumidor é essencial para qualquer mercado, principalmente no entendimento e previsão de demanda. No turismo não é diferente. A demanda turística é um processo de consumo influenciado por diversos fatores que podem ser a combinação de desejos e necessidades, disponibilidade de tempo e dinheiro ou imagens, percepções e atitude. Por isso, para um completo entendimento do comportamento do consumidor no turismo, é necessário um estudo dessas variáveis.

\begin{tabular}{|c|c|c|c|c|}
\hline $\begin{array}{l}\text { Estímulos } \\
\text { de } \\
\text { Marketing }\end{array}$ & $\begin{array}{l}\text { Outros } \\
\text { Estímulos }\end{array}$ & $\begin{array}{l}\text { Características } \\
\text { do comprador }\end{array}$ & $\begin{array}{l}\text { Processo de Decisão } \\
\text { do comprador }\end{array}$ & $\begin{array}{l}\text { Decisões do } \\
\text { comprador }\end{array}$ \\
\hline Produto & Econômico & Culturais & $\begin{array}{l}\text { Reconhecimento de } \\
\text { problemas } \\
\text { Busca de }\end{array}$ & $\begin{array}{l}\text { Escolha do } \\
\text { produto } \\
\text { Escolha da marca }\end{array}$ \\
\hline Preço & Tecnológico & Sociais & $\begin{array}{l}\text { informações } \\
\text { Avaliação de } \\
\text { alternativas }\end{array}$ & $\begin{array}{l}\text { Escolha do } \\
\text { revendedor }\end{array}$ \\
\hline Praça & Político & Pessoais & $\begin{array}{l}\text { Decisão de } \\
\text { compra }\end{array}$ & $\begin{array}{l}\text { Freqüência de } \\
\text { compra }\end{array}$ \\
\hline Promoção & Cultural & Psicológicos & $\begin{array}{l}\text { Comportamento pós } \\
\text { compra }\end{array}$ & $\begin{array}{l}\text { Montante de } \\
\text { compra }\end{array}$ \\
\hline
\end{tabular}

Figura 1.1 Modelo de estímulo e resposta (Kotler, 2002).

O ponto de partida para compreender o comportamento do consumidor é o modelo de estímulo e resposta de Kotler (2002, p.162). Estímulos ambientais e de marketing penetram no consciente do consumidor. Suas características e processos de decisão levam a certas decisões de compra. A tarefa do profissional de marketing é entender o que acontece no consciente do consumidor entre a chegada do estímulo externo e a decisão de compra. 


\section{1 - Os fundamentos do comportamento do consumidor e o turismo}

Cooper et al (2001, p. 63), definem o processo de decisão do consumidor como um sistema formado por quatro elementos básicos:

1. Energizadores de demanda: são as forças de motivação que levam um turista a decidir visitar uma atração ou sair de férias.

2. Efetivadores de demanda: o consumidor terá desenvolvido idéias a respeito de uma destinação, um produto ou organização, por meio de um processo de aprendizagem, atitudes e associações, a partir de mensagens promocionais e informação. Isso afetará a imagem do consumidor e o conhecimento de um produto turístico, servindo assim para elevar ou diminuir os vários energizadores que levam à ação do consumidor.

3. Os papéis e o processo de decisão: o papel importante é aquele do membro da família que está normalmente envolvido nos diferentes estágios do processo de aquisição e na resolução final das decisões sobre quando, onde e como o grupo irá consumir o produto turístico.

4. Determinantes da demanda: o processo de tomada de decisões do consumidor de turismo é sustentado pelos determinantes da demanda. Ainda que possa haver motivação, a demanda é filtrada, limitada e canalizada devido a fatores econômicos (renda), sociológicos (grupos de referência, valores culturais, religiosos) ou psicológicos (percepção de risco, personalidade, atitudes). 
Esses elementos são simplificados no quadro a seguir:

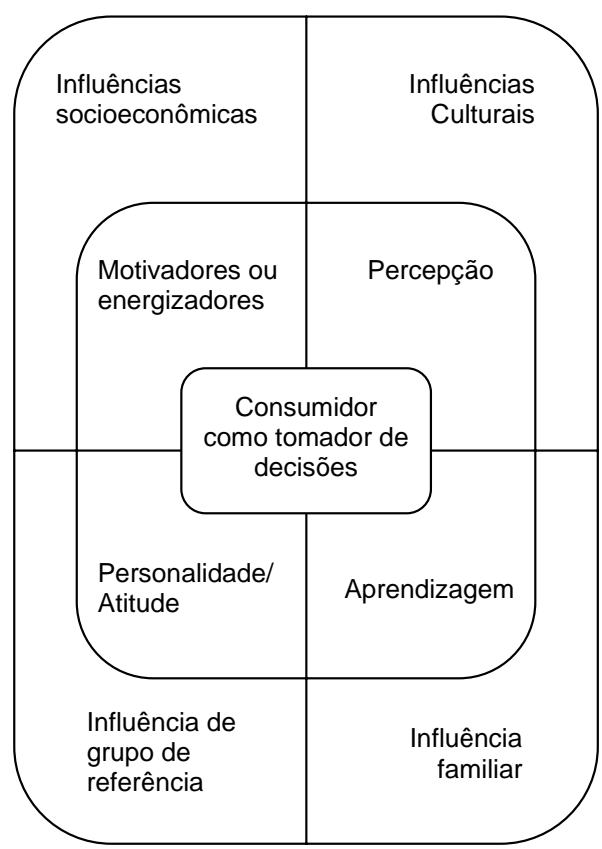

Figura 1.2 Processo de decisão do consumidor em turismo

(Cooper et al, 2001).

\section{2 - Energizadores e Efetivadores de demanda}

\subsection{1 - Motivação}

Motivar significa fazer uma pessoa agir de uma certa maneira, ou estimular o seu interesse. Motivo também está relacionado com iniciar um movimento ou induzir uma pessoa a agir. Para o turismo, a motivação é o ponto de partida do processo de consumo de um produto turístico. Daí a necessidade de ser estudada.

\subsection{2 - A hierarquia das necessidades de Maslow}

A hierarquia das necessidades de Maslow talvez seja a mais conhecida teoria da motivação. Em resumo, ele sugeriu que as necessidades humanas como elementos motivadores formam uma hierarquia. 


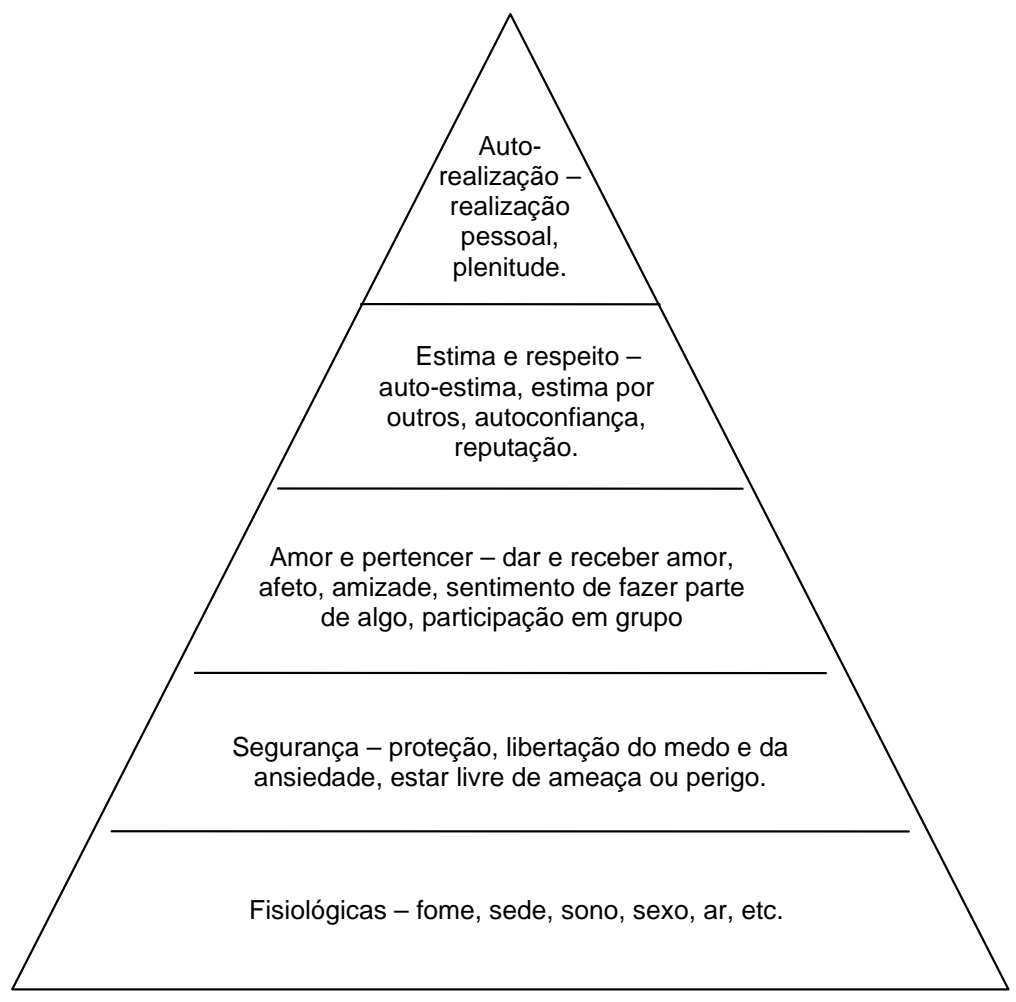

Figura 1.3 Hierarquia das necessidades

(Adaptação de Maslow, 1943).

Maslow afirmava que se nenhuma das necessidades da hierarquia fosse satisfeita, então as necessidades no nível mais baixo, as fisiológicas, dominariam o comportamento. Mas se essas fossem satisfeitas, não serviriam mais de motivação e o indivíduo seria motivado pelo nível seguinte da hierarquia, continuando a subir na hierarquia à medida que as necessidades de cada patamar fossem satisfeitas.

O turismo relaciona-se com praticamente todas os motivadores de Maslow, desde as necessidades fisiológicas de sexo, passando pela sensação de pertencer até chegar ao fator status. 
A hierarquia das necessidades, apesar de ser a mais conhecida, talvez por sua simplicidade, recebeu algumas críticas. Porém, não cabe a este trabalho julgá-las.

\subsection{3 - Motivação em Turismo}

$\mathrm{Na}$ década de 50, as pesquisas apontavam o prestígio social (status) como a principal motivação para as viagens turísticas. Porém, segundo Alvim (2002, p.1), apesar desse fator ainda aparecer como uma das principais motivações turísticas, ele tem sido superado pela fuga do cotidiano.

McIntosh, Goeldner e Ritchie (1995) utilizam quatro categorias de motivação para o turismo:

1. Motivadores físicos: são aqueles relacionados ao relaxamento do corpo e da mente, à questão de saúde, aos esportes e ao prazer. Este grupo de motivadores é considerado ligado àquelas atividades que reduzem a tensão.

2. Motivadores culturais: são aqueles identificados pelo desejo de ver e conhecer mais sobre outras culturas, aprender sobre os nativos de um país, seu estilo de vida, música, arte, folclore, dança, etc.

3. Motivadores interpessoais: este grupo inclui o desejo de conhecer novas pessoas, visitar parentes ou amigos e buscar novas e diferentes experiências. A viagem é um escape dos relacionamentos de rotina com amigos e vizinhos, ou do ambiente doméstico, ou é usada por razões espirituais.

4. Motivadores de status e prestígio: incluem um desejo de continuação da educação (ou seja, desenvolvimento pessoal, satisfação do ego e satisfação dos sentidos). Tais motivadores estão relacionados com o desejo de reconhecimento e atenção de outros, como forma de estimular o ego. Esta categoria também inclui o desenvolvimento pessoal com relação ao desenvolvimento de hobbies e atividades de educação. 
Em resumo, nota-se que os conceitos de motivação relacionados a viagens, incluem:

- A idéia de que viagens estão inicialmente relacionadas a necessidades, e que isto se manifesta em termos de desejos, e à força da motivação ou impulso como o energizador da ação;

- A motivação é baseada em aspectos sociológicos ou psicológicos de normas, atitudes, cultura e percepção adquirida, levando a formas de motivações específicas de cada pessoa;

- A imagem da destinação, criada por meio dos vários canais de comunicação, irá influenciar a motivação e, posteriormente, afetar o tipo de viagem escolhida.

\section{3 - Os papéis e o processo de tomada de decisões no turismo.}

\subsection{1 - Tipologias de turistas}

Os turistas podem ser classificados em diferentes tipologias ou papéis que exercitam a motivação como forma energizante, vinculada a necessidades pessoais. Utilizando essa abordagem, os papéis podem ser estudados em relação às formas de comportamento que se orientam por objetivos, ou pela atividade de escolha da destinação.

Um dos principais estudos teóricos enfocando os aspectos sociológicos dos papéis em turismo foi desenvolvido por Cohen $(1972,1974,1984)$. A interação dos atributos de personalidade, como atitude, percepções e motivação, permite que sejam identificados diferentes tipos de papel dos turistas. Cohen utiliza uma classificação baseada na teoria de que o turismo combina a curiosidade de procurar novas experiências com a necessidade de assegurar aspectos familiares que lembrem a própria casa. Ele propõe uma seqüência contínua de combinações possíveis de novidade e familiaridade e, desmembrando essa seqüência em combinações típicas desses dois componentes, classifica os turistas em quatro categorias. 
O turista de grupos organizados

Pouco Aventureiro, está ansioso para

preservar sua "redoma de vidro

ambiental" durante sua viagem.

Geralmente compra um pacote pronto, é

guiado pela destinação, tendo pouco

contato com o povo ou a cultura locais

Turismo institucionalizado

Os operadores da indústria

turística, agentes de viagem,

donos ou gerentes de hotel

O turista de pacotes turísticos individuais Semelhante ao citado acima, mas com mais flexibilidade e espaço para a escolha pessoal. Entretanto, a viagem ainda é organizada pela indústria turística

e a "redoma de vidro ambiental" o protege operadores de transportes lidam com ele diariamente.

\section{O explorador}

A viagem é organizada por conta própria

tentando sair do roteiro comum. Todavia,

busca a hospedagem confortável e o

transporte confiável e, ao mesmo tempo

em que a "redoma de vidro" ambiental é

abandonada ocasionalmente, ela

permanece lá para que possa entrar nela

se as coisa ficarem difíceis.

O Andarilho

Todas as conexões com a indústria

turística são rejeitadas e a viagem será

uma tentativa de ir ao mais longe de casa

e da familiaridade quanto possível. Sem

itinerário fixo, o andarilho vive com o povo

local, pagando pelo que necessita e

penetrando em sua cultura.

Turismo não-institucionalizado

Viagem individual, rejeitando

contato com a indústria turística exceto quando for absolutamente necessário.

Figura 1.4 Classificação de turistas de Cohen (Boniface and Cooper, 1987; adaptado de Cohen, 1972; em Cooper et al, 2001).

Ao mesmo tempo em que podem desfrutar as destinações como novidade, os turistas preferem fazê-lo a partir de uma base familiar. O grau de familiaridade dessa base fundamenta a tipologia de Cohen, na qual o autor identifica quatro papéis para os turistas: o turista de grupos organizados, o turista de pacotes turísticos individuais, o explorador e o andarilho. Os dois primeiros papéis são institucionalizados e os seguintes não-institucionalizados. Ele estava interessado em classificar os grupos, não para entender a demanda, mas os efeitos ou o impacto 
das formas institucionalizadas de turismo, que considerou como questões de autenticidade, padronização de destinações, festejos e desenvolvimento de instalações. Ele também identificou o impacto das formas não-institucionalizadas de turismo sobre a destinação, o qual ele verificou que funciona como "ponta-de-lança para o turismo de massas" e tem um "efeito demonstração" sobre os grupos socioeconômicos inferiores do núcleo receptor.

\subsection{2 - O papel e a influência da família}

Cada membro de uma família cumpre um papel especial dentro do grupo. Ele pode ser marido/pai, esposa/mãe, filho/irmão, filha irmã. A tomada de decisão familiar designa papéis para cada um desses membros, podendo ser compartilhada ou caber a uma só pessoa. Por exemplo, os filhos podem ser responsáveis pela coleta de informações, atuando como influenciadores, a mãe pode ser a decisora e o pai o efetivo comprador de um produto turístico.

\subsection{3 - A importância da imagem}

A visão que se tem do mundo é feita de experiências, aprendizados, emoções e percepções ou, mais precisamente, da avaliação cognitiva dos elementos citados acima. Essa visão poder ser descrita como conhecimento, produzindo uma imagem específica do mundo.

A imagem é de importância fundamental para a preferência, a motivação e o comportamento de um indivíduo com relação a produtos e destinações turísticas, já que irá fornecer um efeito "impulso" que resultará em diferentes prognósticos de demanda.

O comportamento turístico, tanto de indivíduos como de grupos, depende de sua imagem sobre situações imediatas e do mundo. A noção de imagem está intimamente relacionada ao comportamento e à atitude os quais são estabelecidos com base na imagem presumida de uma pessoa e não mudam facilmente, a não ser que nova informação ou experiência seja adquirida. 


\section{4 - Determinantes da demanda turística}

Uma vez tomada a decisão de viajar, a capacidade de fazer a viagem e a natureza da viagem serão determinadas por um amplo leque de fatores inter-relacionados. Esses fatores podem ser divididos, de forma ampla, em dois grupos: estilo de vida e ciclo de vida.

\subsection{1 - Estilo de vida}

Estão inclusos em fatores de estilo de vida, renda e emprego (já que o turismo é uma atividade cara); direito a férias pagas; grau de instrução (educação); mobilidade; raça, sexo e religião.

A segmentação de valores e estilo de vida vem sendo pesquisada por empresas e utilizada como uma técnica de segmentação de mercado nos Estados Unidos. Mesmo não tendo sido projetada para o turismo, esclarece um pouco o comportamento nessa área. Tenta-se combinar variáveis demográficas com as necessidades, as atitudes e os desejos das pessoas. Os estilos de vida são classificados como segue:

\section{Grupos movidos por necessidades}

Aqui as necessidades são maiores que as escolhas, já que os indivíduos são pobres ou, de alguma forma, desfavorecidos. Há dois tipos neste estilo de vida:

- Sobrevivente - os grupos mais desfavorecidos, excluídos do centro da sociedade

- Sustentador - um grupo que está lutando para se manter, mas tem esperanças de que as circunstâncias irão se modificar

\section{Grupos direcionados para fora}

Estão preocupados com a forma com que parecem aos outros, de forma que vivem e comportam-se de acordo com as percepções de outras pessoas. Há três tipos:

- Pertencentes - grupo conservador, confortável e convencional

- Emulador - não muito satisfeitos, conscientes de seu status, competitivos, ambiciosos e geralmente jovens

- Empreendedor - grupo bem-sucedido, feliz e esforçado, de meia-idade, próspero, seguro de si, são os líderes da sociedade

\section{Grupos direcionados para dentro}

Estilos de vida que têm mais a ver com a satisfação interior do que com as opiniões de outras pessoas. Há quatro tipos:

- $\quad$ Eu sou mais eu - muito jovens, impulsivos e confusos e extremamente individualistas

- Experimentador - joviais, em busca de experiência, voltados para o crescimento interior, artísticos

- Socialmente consciente - grupo orientado por missões, adotando, por exemplo, preocupações ambientais; são maduros e bem sucedidos

- Voltado para si - grupo que considera importante a recompensa emocional; não são motivados por opiniões externas a seu respeito, ou por recompensas materiais

Figura 1.5 Categorias de Valores e Estilo de Vida (Cooper et al, 2001, adaptado de Shih, 1986). 


\subsection{2 - Ciclo da vida}

A propensão ao turismo e o tipo de experiência turística demandada estão intimamente relacionados à idade de um indivíduo. Apesar da idade cronológica ser a mais convencional, a "idade doméstica", que se refere ao estágio alcançado pelo indivíduo no ciclo da vida, é mais adequada para se analisar a demanda turística. É o que pode ser visto no quadro abaixo:

\section{Infância}

Neste estágio, as decisões são tomadas pelo indivíduo, em termos de férias, ainda que, é claro, as crianças tenham uma influência significativa e cada vez maior nas decisões de seus pais. Na idade de 10 ou 11 anos, algumas crianças saem em férias organizadas pela escola ou por grupos sociais. Geralmente são férias domésticas, com os arranjos feitos por conta própria.

\section{Adolescente/Jovem adulto}

Neste estágio, a preocupação é com a independência, a convivência e uma busca de identidade. Como regra geral, as férias independentes dos pais começam em torno dos 15 anos, limitadas pela falta de recursos financeiros mas compensadas por ter poucos compromissos, bastante tempo livre e uma curiosidade em conhecer novos lugares e experiências. Este grupo tem uma alta propensão à viagem, principalmente em férias planejadas utilizando transporte de superfície e hospedagens organizadas por conta própria. Aqui, a preocupação é simplesmente sair - a destinação não é importante.

\section{Casamento}

O casamento representa a primeira "crise" em termos de organização das preocupações, interesses e atividades de um indivíduo. As preocupações voltam-se para o meio de vida e os investimentos para a vida toda. Antes da chegada dos filhos, os jovens casais muitas vezes têm uma renda alta e poucos vínculos, o que lhes dá uma alta propensão à viagem, freqüentemente para o exterior. A chegada dos filhos representa uma segunda "crise", a qual, somada à responsabilidade de um lar, pode significar que as restrições de tempo e finanças diminuam a propensão à viagem. As férias se tornam mais organizacionais do que geográficas, sendo que o turismo doméstico, hospedagens por conta própria e a visita a amigos e parentes se tornam cada vez mais comuns.

Figura 1.6 Idade doméstica e demanda turística (Adaptado de Cooper et al, 2001).

Isso porque o ciclo não é apenas uma progressão por fase ou idade, mas representa prováveis flutuações na renda disponível e mudanças nas responsabilidades sociais, fatores que influenciam diretamente essa demanda. Wells e Gubar (1966) conceitualizaram o ciclo de vida das famílias nos Estados Unidos, desde o solteiro até o estágio do sobrevivente solitário: 
1. Estágio do solteiro: pessoas solteiras que não vivem na casa dos pais.

2. Recém-casados: jovens, sem filhos.

3. Ninho Cheio I: casais jovens com filhos dependentes.

4. Ninho Cheio II: casais jovens com filhos dependentes acima de seis anos.

5. Ninho Cheio III: casais com filhos dependentes.

6. Ninho Vazio: casais mais velhos sem filhos que morem com eles. Chefe de família dentro do mercado de trabalho.

7. Como descrito acima, mas com chefe de família aposentado.

8. Sobrevivente solitário: pessoas solteiras mais velhas, dentro do mercado de trabalho.

9. Como descrito acima, mas aposentado.

A distinção de cada estágio do ciclo de vida aparece por certo número de fatores combinados, como:

- Preocupações - são as ocupações mentais que surgem das motivações;

- Interesses - que são os sentimentos do que um indivíduo gostaria de fazer, ou representam a consciência de uma idéia ou oportunidade;

- Atividades - que são as ações de um indivíduo.

\section{5 - Demanda turística reprimida}

São razões pelas quais as pessoas não viajam:

- Viajar é uma atividade cara e demanda certo nível de renda antes que as pessoas possam entrar no mercado. Ela compete com outros produtos pelos recursos financeiros disponíveis.

- A falta de tempo é um problema para alguns indivíduos que não podem reservar períodos suficientes para estar longe de casa devido ao trabalho ou à família.

- Limitações físicas (como saúde precária).

- Circunstâncias familiares, como as vividas por aqueles que são pais ou mães solteiros ou têm que tomar conta de parentes idosos.

- Restrições governamentais, como controle de moeda e vistos. 
- A falta de interesse/medo.

\section{6 - Modelos da demanda turística}

A partir dos fatores analisados anteriormente, como atitudes, percepções, imagens, papéis, motivações e determinantes, muitos pesquisadores tentaram uni-los e estruturá-los em modelos.

Podem ser identificadas três fases que caracterizam o desenvolvimento da teoria de comportamento do consumidor:

1. Fase empírica (1930 a 1940), caracterizada pela tentativa de identificar, na indústria, os efeitos das decisões referentes à distribuição, propaganda e promoções, tendo como base as teorias econômicas.

2. Fase da pesquisa motivacional (década de 1950), caracterizada pelos conceitos freudianos relacionados às pulsões. Muito dessa teoria baseava-se na idéia da existência de necessidades instintivas que residem no id e são governadas pelo ego, que age para equilibrar instintos irrestritos e limites sociais. O superego, por sua vez, era visto como a incorporação de valores, mas com um limitador de ação, com base nas restrições morais. O problema principal era a ênfase nas necessidades inconscientes que são, por definição, muito difíceis de serem provadas empiricamente.

3. Fase Formativa (década de 1960), em que os modelos de comportamento do consumidor foram concebidos e provaram ser úteis como meio de organizar o conhecimento disperso da ação social. Os principais teóricos desenvolveram "grandes modelos" de comportamento do consumidor, que foram utilizados posteriormente ou transformados pelos autores interessados no processo de escolha do turismo.

Engel, Blackwell e Miniard (1986, apud Cooper et al, 2001, p. 85) classificaram os modelos de acordo com o grau do comportamento de bisca ou solução de problemas por parte do consumidor: 
- Modelos limitados para solução de problemas (limited problem solving - LPS) são aplicáveis a aquisições reétidas ou comuns, com um baixo nível de envolvimento do consumidor. Tirando-se os casos de viagens curtas, não se aplicam ao turismo.

- Modelos ampliados para a solução de problemas (extended problem solving EPS) aplicam-se a aquisições associadas a altos níveis de risco percebido e envolvimento, nas quais a busca de informação e a avaliação de alternativas cumprem papel importante na decisão de compras. A grande maioria dos modelos de comportamento do turista está dentro dessa categoria.

Devido ao custo, ao fator de risco e ao alto envolvimento em uma compra de turismo, alguns modelos de comportamento do consumidor que buscam explicar comportamentos de baixo envolvimento relacionados à aquisição são menos relevantes e, portanto, não foram considerados aqui. Os exemplos seguintes são de modelos EPS.

1.6.1 - Wahab, Crampon e Rothfield (1976)

Uma das primeiras tentativas de entendimento do comportamento de compra no turismo foi feita por Wahab, Crampon e Rothfield apud Cooper et al (2001, p. 85) apresentando o consumidor agindo de forma intencional, conceitualizando seu comportamento de compra em termos de singularidade da decisão de compra:

- Sem retorno tangível do investimento;

- Despesas consideráveis em relação à renda;

- Aquisição não espontânea, nem regida por caprichos;

- Gastos envolvendo economias e planejamento prévio.

Esse modelo baseia-se nos grandes modelos de comportamento do consumidor vigentes na época. 


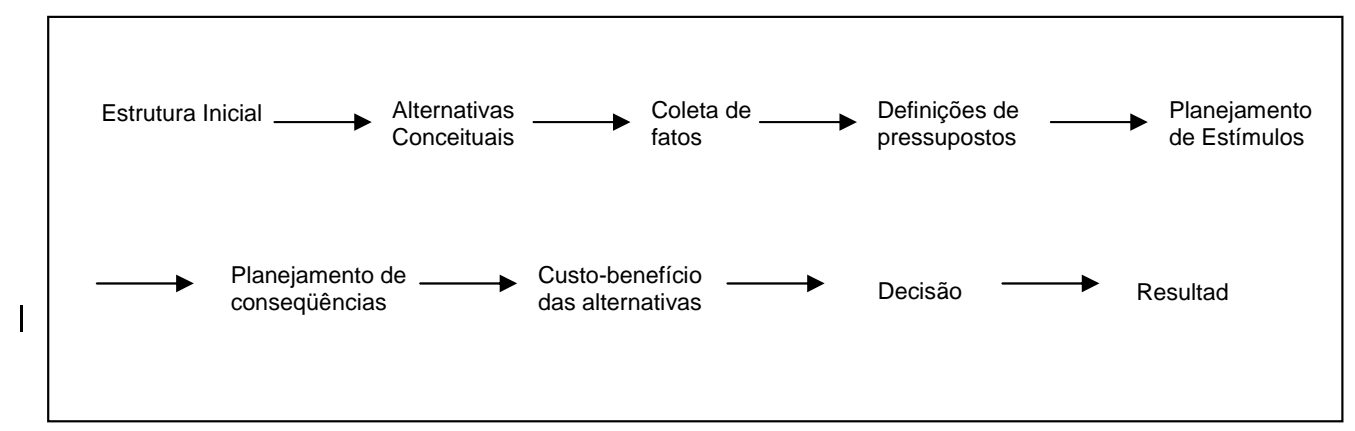

Figura 1.7 Modelo de comportamento do consumidor (Cooper et al, 2001, adaptado de Wahab, Crampon e Rothfield, 1976).

\subsection{2 - Schmoll (1977)}

Schmoll apud Cooper et al (2001, p. 85) afirma que a criação de um modelo de processo de decisões sobre viagens não era apenas um exercício teórico, já que seu valor poderia ser encontrado em sua contribuição para a tomada de decisões em viagens. Seu modelo baseava-se nos modelos de Howard-Sheth (1969) e Nicosia (1966) de comportamento do consumidor.

O modelo de Schmoll era construído com base em motivações, desejos, necessidades e expectativas como sendo determinantes pessoais e sociais do comportamento relacionado a viagens. Estes são influenciados por estímulos à viagem, confiança do viajante, imagem da destinação, experiência prévia e restrições de custo e tempo. O modelo possui quatro campos, cada um deles exercendo alguma influência sobre a decisão final. Segundo Schmoll apud Cooper et al (2001, p. 86), a decisão final (escolha de uma destinação, da época da viagem, do tipo de hospedagem, do tipo de arranjos de viagem e outros) é, na verdade, o resultado de um processo distinto que envolve vários estágios ou campos sucessivos.

- Campo 1: Estímulos de viagem. Inclui estímulos externos na forma de comunicação promocional, recomendações pessoais e comerciais. 
- Campo 2: Determinantes pessoais e sociais. Determinam os objetivos do consumidor na forma de necessidades e desejos de viagem, expectativas e riscos objetivos e subjetivos associados ao ato de viajar.

- Campo 3: Variáveis externas. Envolvem a confiança do viajante no prestador do serviço, a imagem da destinação, a experiência adquirida e as restrições de custo e tempo.

- Campo 4: Consiste das características relacionadas à destinação ou ao serviço que exerce influência na decisão e seus resultados.

No modelo de Schmoll, é introduzida a importância da imagem, que cumpre papel significativo no processo de demanda.

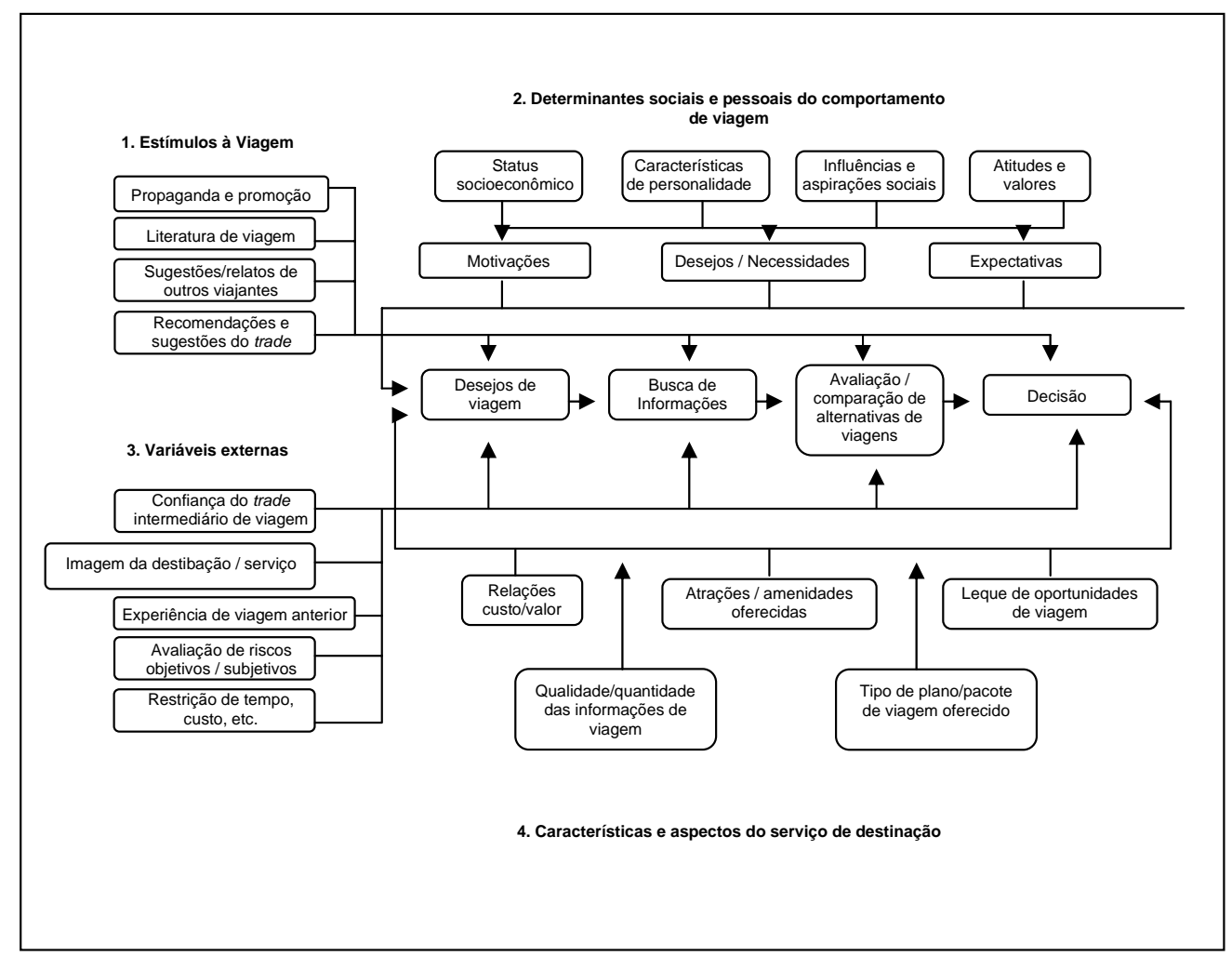

Figura 1.8 Modelo de Schmoll (Cooper et al, 2001, adaptado de Schmoll, 1977). 
1.6.3 - Mayo e Jarvis (1981)

Mayo e Jarvis apud Cooper et al (2001, p. 87) também tomaram emprestados elementos dos modelos dos grandes teóricos. Eles aproveitaram basicamente a abordagem do processo de decisão em três estágios de Howard-Sheth, na qual a solução de problemas é vista como ampliada, limitada ou rotineira.

Eles descrevem a tomada de decisões ampliada (ex: aquisição da destinação) como sendo caracterizada por uma necessidade percebida de uma fase de busca de informações e pela necessidade de um período mais longo de tomada de decisões. A busca pela informação e sua avaliação é apresentada como componente principal do processo de tomada de decisões, no qual o conhecimento do consumidor vai de noções gerais a critérios e preferências mais específicas pelas alternativas.

Mayo e Jarvis argumentam que viajar é uma forma especial de comportamento do consumo, envolvendo uma aquisição intangível e heterogênea de um produto com caráter de experiência. Mesmo assim, eles não desenvolveram nenhuma teoria baseada em atividades.

1.6.4 - Mathieson e Wall (1982)

Formatado: Português

Mathieson e Wall apud Cooper et al (2001, p. 87) apresentam um processo de cinco estágios sobre o comportamento na compra de viagens. 


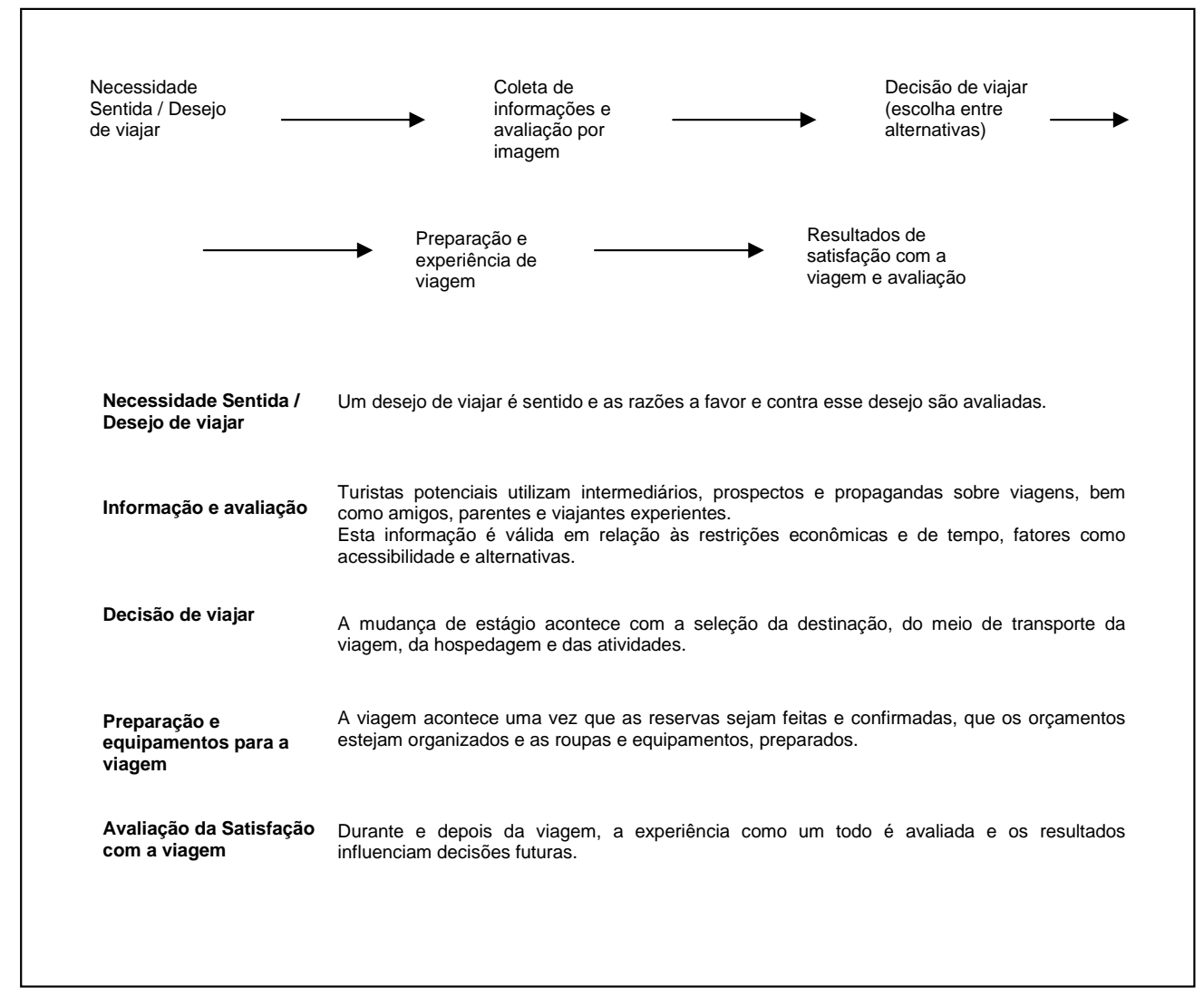

Figura 1.9 Comportamento na compra de viagens (Cooper et al, 2001, adaptado de Mathieson e Wall, 1982).

Sua estrutura é influenciada por quatro fatores inter-relacionados:

1. Perfil do turista (idade, educação, tipo de renda, experiência prévia e motivações)

2. Percepção sobre a viagem (imagem das instalações e dos serviços de uma destinação, os quais se baseiam na credibilidade da fonte)

3. Recursos e características da destinação (atrações e aspectos de uma destinação)

4. Características da viagem (distância, duração da viagem e risco percebido sobre a área visitada) 


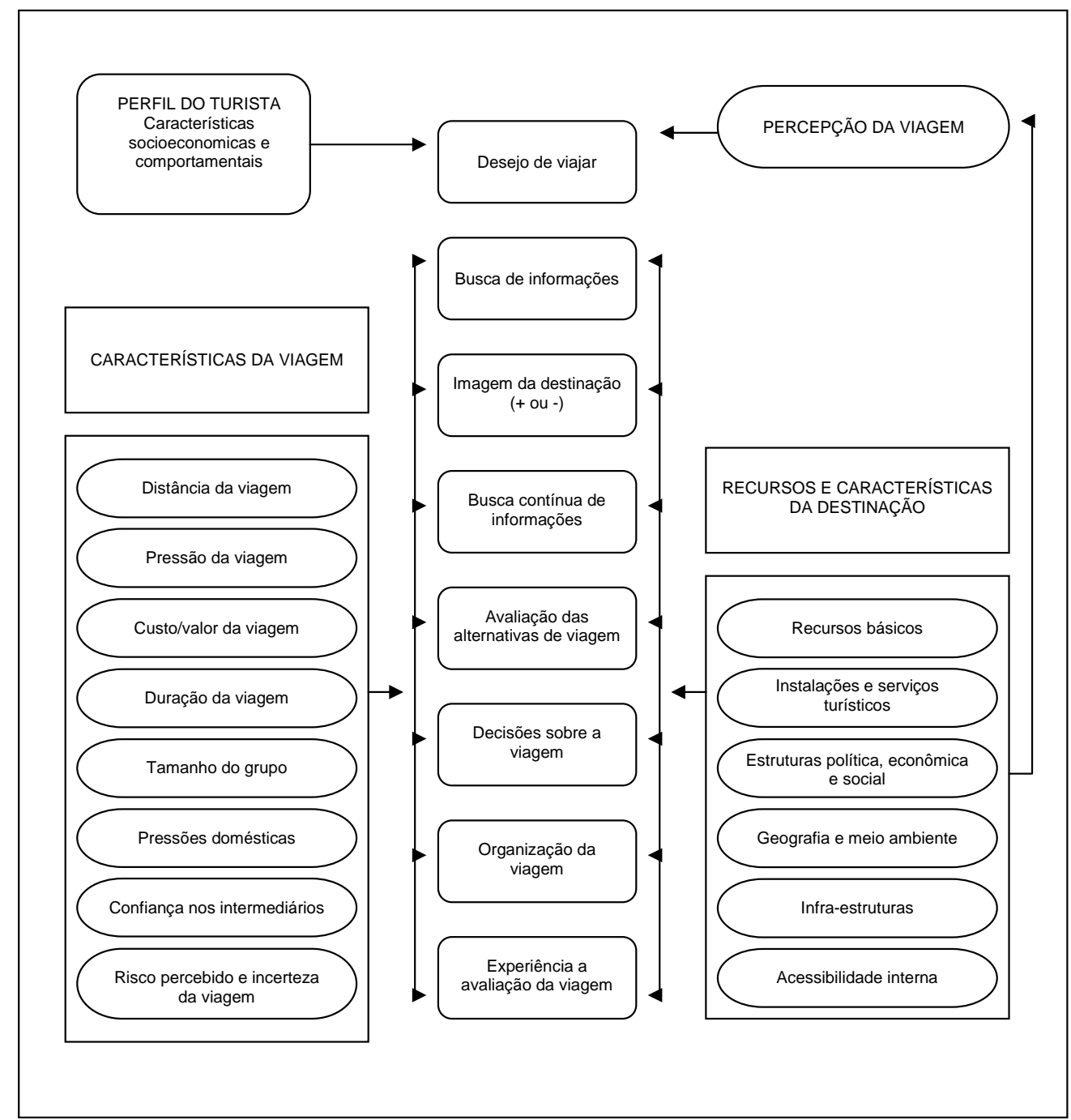

Figura 1.10 Modelo de Mathieson e Wall (Cooper et al, 2001, adaptado de Mathieson e Wall, 1982).

Além disso, Mathieson e Wall reconhecem que a viagem é um serviço com características de intangibilidade, perecibilidade e heterogeneidade, o que afeta, de uma forma ou de outra a tomada de decisão do consumidor.

\subsection{5 - Woodside e Lysonski (1989)}

Neste modelo, Woodside e Lysonki apud Leal (2002) destacam que para um viajante escolher a destinação, ele necessita, primeiramente, de informações que o deixem 
ciente da existência delas. Deste conjunto inicial, ele terá preferência por algumas e variáveis de momento permitirão uma decisão final sobre para qual ele viajará.

Entre as variáveis pessoais que influenciam o início do processo de escolha da destinação estão as experiências prévias com destinações, estilo de vida, faixa etária, etc. Além dessas, as variáveis de marketing também estão presentes neste primeiro momento, como o preço e a publicidade. Estas duas categorias de variáveis, segundo os autores, levam o viajante a um conjunto de destinações conhecidas. Este conjunto se divide em destinações possíveis e impossíveis de serem visitadas, em destinações que remetem a experiências desagradáveis e as que não geram nenhum tipo de sentimento (positivo ou negativo).

É neste momento que associações afetivas induzem o viajante a preferir determinada destinação em relação à outra. Havendo a intenção de visitá-la e variáveis de momento que permitam a sua visitação, esta destinação será a escolhida. Vale ressaltar que o processo pode ser encurtado quando o viajante já possui uma ou mais destinações preferidas.

A análise deste modelo demonstra a importância da imagem das destinações quando o mesmo ressalta as variáveis de marketing e a sua importância para o início do processo. Sem as imagens das destinações, não há como o viajante chegar a um conjunto de destinações preferidas e nem como selecionar uma delas para visitação, conseqüentemente.

1.6.6 - Um e Crompton (1990)

O modelo de Um e Crompton (1990) é bastante similar ao de Woodside e Lysonski. No entanto, um conjunto de destinações conhecidas já é o ponto de partida para o processo de escolha. Este conjunto é influenciado por fatores externos e internos que geram um conjunto menor de destinações, possibilitando a decisão.

A formação deste conjunto inicial de destinações conhecidas pelo viajante é influenciada pelos fatores externos, ou seja, experiências prévias com uma destinação, textos e imagens de material promocional e mídia, e informações e 
comentários de outros viajantes. Os autores definem os fatores externos como "a soma das interações sociais e comunicações de marketing às quais o potencial viajante está exposto" (p. 434) (tradução livre). Vale ressaltar que a obtenção destas informações neste momento é feita de forma passiva, o viajante não procura por elas.

A evolução deste conjunto inicial para um outro com um número reduzido de destinações acontece com base nos fatores internos. Estes são citados pelos criadores do modelo como "oriundos de características sócio-psicológicas de um potencial viajante e incluem características pessoais [...], motivações, valores e atitudes“ (Assael, 1984 apud Um e Crompton, 1990, p. 436-7) (tradução livre).

Uma busca por informações sobre as destinações pré-selecionadas permite um maior conhecimento das possibilidades e, posteriormente, a escolha da destinação para onde o potencial viajante irá se locomover para realizar a sua viagem.

Outra vez, percebe-se que a imagem das destinações é fator decisivo no processo de escolha das mesmas. Para que um potencial visitante pense na possibilidade de ir até uma destinação, ele tem que ter alguma exposição prévia à mesma - inclusive por meio de imagens.

1.6.7 - Moscardo et al. (1996)

Moscardo et al. apud Cooper et al (2001, p.88) forneceram uma abordagem diferente do comportamento do consumidor, ao enfatizar a importância das atividades como um vínculo fundamental entre a viagem e a escolha da destinação. Eles argumentam que os motivos dão aos viajantes expectativas de atividades, que passam a ver nas destinações a oferta dessas atividades. Neste modelo, Moscardo et al. apresentaram uma possibilidade de uso prático dele pelos profissionais de marketing. Eles argumentam que os segmentos de viajantes que buscam atividades podem ser associados a atividades na destinação por meio de estratégias de comunicação e de desenvolvimento de produtos. 


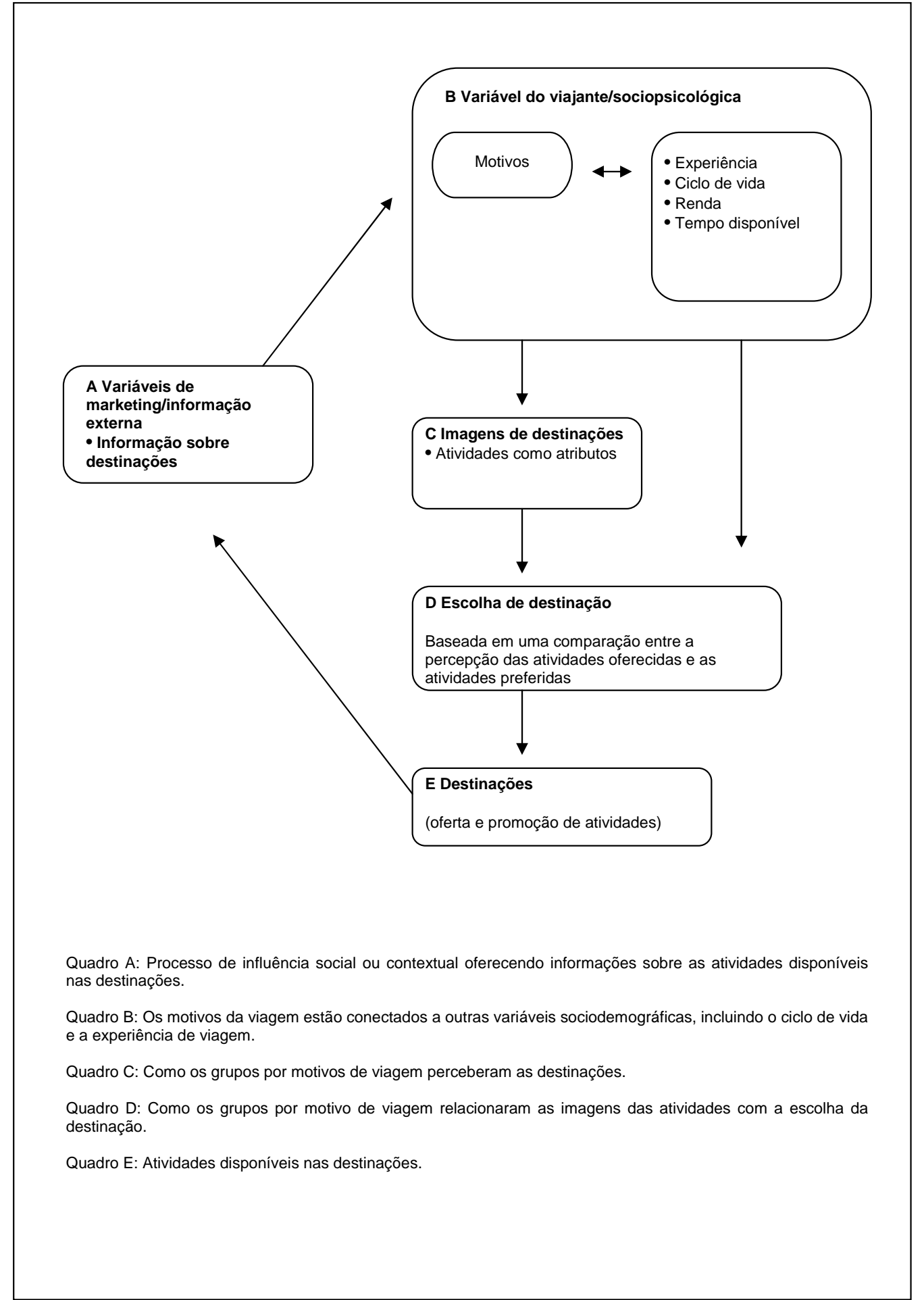

Figura 1.11 Modelo de escolha de destinação baseada em atividades (Cooper et al, 2001, adaptado de Moscardo et al, 1996). 


\section{2 - IMAGEM DA DESTINAÇÃO TURÍSTICA}

Como foi visto no capítulo anterior e Mayo (1975, p. 15) sustenta em seu artigo, a imagem da destinação turística é um fator crítico no processo de escolha do turista. Ela influencia a escolha de qual local visitar, o comportamento do turista na destinação, o nível de satisfação e as lembranças da experiência. Ou seja, ela está presente em toda experiência de consumo, desde o estímulo, a satisfação até o pósvenda. Por isso, uma análise detalhada de como a imagem é formada e das técnicas de mensuração disponíveis fazem-se necessárias na medida em que podem ajudar os planejadores da indústria turística a tomarem decisões que aumentem o fluxo de turistas e atendam as suas necessidades.

\section{1 - O que são imagens de destinações turísticas?}

Definir o significado do termo "imagem de uma destinação turística" é bastante complexo. Principalmente porque o termo "imagem" tem uma conotação tão popular que é difícil dotar-lhe de uma definição acadêmica (Pearce, 1988, apud Leal, 2002). Tanto que o dicionário Aurélio apresenta mais de 16 definições para o termo.

Do ponto de vista da psicologia, "imagem" está relacionada à representação visual. Já do ponto de vista do marketing, o termo refere-se ao posicionamento de produto e ao comportamento do consumidor ou grupo de consumidores (segmento).

A definição de imagem de uma destinação turística mais comum é "a soma de crenças, idéias e impressões que uma pessoa tem de uma destinação" (Crompton, 1979, apud Jenkins, 1999). Porém, ela baseia-se no indivíduo, furtando-se dos aspectos da imagem compartilhada por grupos, os estereótipos, muito importantes para os estudos de mercado. Por isso, a definição escolhida para nortear o trabalho é a de Lawson e Baud Bovy (1977): "a expressão de todo conhecimento objetivo, impressões, preconceitos, imaginações e emoções que um indivíduo ou grupo tem de um lugar em particular". 
Abaixo, segue lista com as principais definições de imagem, realizada por Gallarza et al (2002):

Hunt (1971): Impressões que uma pessoa ou pessoas têm sobre um estado no qual eles não residem.

Markin (1974): Nosso próprio, personalizado, internalizado e conceitualizado entendimento do que conhecemos.

Lawson and Bond-Bovy (1977): a expressão de todo conhecimento objetivo, impressões, preconceitos, imaginações e emoções que um indivíduo ou grupo tem de um lugar em particular.

Crompton (1979): a soma de crenças, idéias e impressões que uma pessoa tem de uma destinação.

Dichter (1985): O conceito de imagem pode ser aplicado a um candidato político, a um produto e a um país. Ele não descreve traços ou qualidades individuais, mas todas as impressões presentes nas mentes dos consumidores.

Reynolds (1985): Imagem é a construção metal desenvolvida pelo consumidor baseada em uma seleção de poucas impressões entre o total de impressões. Ela vem de um processo criativo no qual as impressões selecionadas são elaboradas, enfeitadas e ordenadas.

Embacher and Buttle (1989): Imagem é o conjunto de idéias e concepções que se tem, individual ou coletivamente, da destinação estudada. A imagem deve englobar tanto os componentes de conhecimento quanto os de avaliação.

Fakeye and Crompton (1991): Imagem é a construção mental desenvolvida pelo turista em potencial com base em uma seleção de poucas impressões entre o total de impressões.

Kotler et al (1994): A imagem de um lugar é a soma de crenças, idéias e impressões que uma pessoa tem dele.

Gartner (1993), (1996): Imagens de destinações são desenvolvidas por três componentes hierarquicamente interrelacionados: cognitivo, afetivo e conativo.

Santos Arrebola (1994): Imagem é a representação mental dos atributos e benefícios percebidos de um produto.

Parenteau (1995): É um pré-julgamento favorável ou desfavorável que o público tem de um produto ou destinação. 


\section{2 - A formação da imagem}

A imagem de um lugar em particular que cada pessoa possui é única, abrangendo suas próprias lembranças, associações e imaginação (Jenkins e McArthur, 1996, p. 11). Stabler (1988) divide os fatores que influenciam a formação da imagem da destinação na cabeça dos consumidores em fatores de demanda e de oferta. O fator de demanda pode ser, grosso modo, comparado à formação orgânica da imagem de Gunn (1972), enquanto o fator de oferta corresponde à formação induzida da imagem.

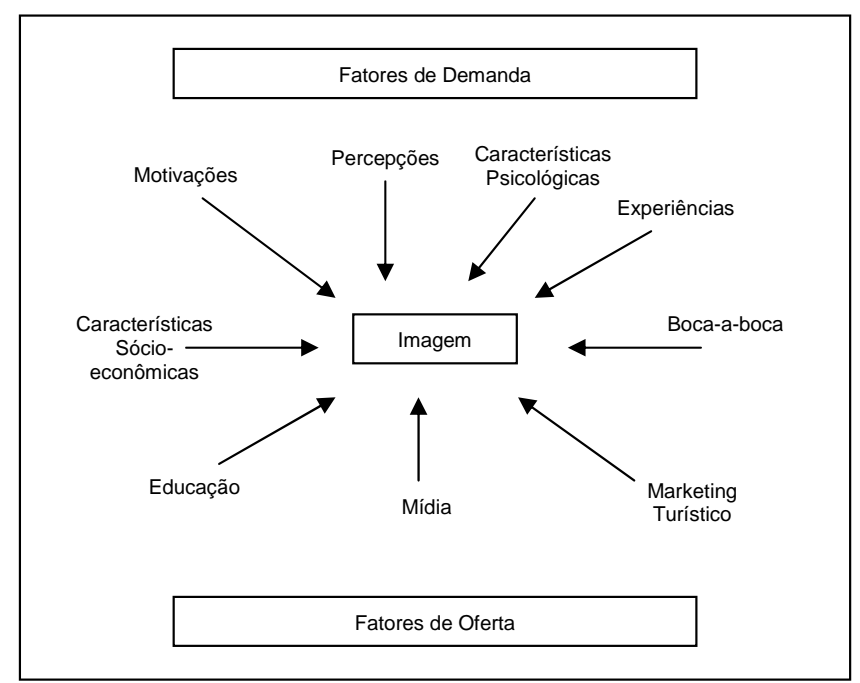

Figura 2.1 Fatores de influência na formação da imagem turística pelos consumidores (Stabler, 1988).

Muitos pesquisadores têm investigado os fatores que influenciam na formação da imagem. Por exemplo, estudos de Hunt (1975) e de Scott et al. (1978) apontaram que a formação da imagem é determinada pela distância da destinação em relação ao local de origem do turista, porque as pessoas estão mais condicionadas a visitarem destinações próximas às suas casas e mais expostas a informações sobre elas pela mídia e pelos amigos e parentes. Concluíram que as pessoas têm imagens mais realistas das destinações próximas a seu local de origem. Esses estudos podem ser validados com base em estatísticas da própria Embratur em que a maioria dos turistas que vêm ao Brasil é dos EUA e da Argentina, locais mais próximos que a Europa ou Ásia, por exemplo. 
Nolan (1976) pesquisou as fontes de informações para viagem usadas pelos turistas domésticos nos EUA. Ele descobriu que a informação usada mais comum era a indicação de amigos e parentes, seguida de guias de viagem, informações comerciais do trade turístico e depois publicações promocionais. Em termos de credibilidade das fontes de informações de viagem, os guias foram classificados em primeiro, enquanto os serviços disponibilizados pelo governo e o conselho de amigos e parentes foram considerados mais informativos. Nolan também mediu o "propósito" das fontes de informações de viagem, pedindo para os entrevistados que classificassem se as fontes eram tendenciosas/não-tendenciosas, e inferiu pelos resultados que a comunicação das informações de viagem (em especial os folhetos de viagem) é tendenciosa.

Apesar dos recentes e constantes estudos, o processo de formação da imagem não é bem entendido e uma estruturação teórica para o seu entendimento faz-se necessária.

Para o estágio inicial do desenvolvimento dessa estruturação, a teoria dos sete estágios de Gunn (1972) é muito útil. A teoria compreende uma constante construção e modificação de imagens, compostas por: imagens orgânicas, informações não-turísticas sobre uma destinação (documentários, programas de TV, livros, exercícios da escola e experiência de amigos); imagens induzidas, informações promocionais (folhetos de viagem, publicidade e propaganda) e imagens induzidas modificadas, resultado da experiência pessoal na destinação. 
1. Acúmulo mental de imagens de um local durante a vida.

\section{$\downarrow$}

2. Alteração das imagens durante a pesquisa anterior à decisão de viajar.

\section{$\downarrow$}

3. A decisão de viajar baseada na eficiência da imagem, experiência prévia, mas limitada por tempo, dinheiro e outras barreiras.

\section{$\checkmark$}

4. Viajar para a destinação pode condicionar a imagem (por exemplo sinalização em estradas,

monumentos, guias).

5. Participação ou experiência na
destinação, atividades,
acomodação e os outros serviços,
todos influenciam a imagem.

IMAGEM ORGÂNICA

IMAGEM INDUZIDA

Figura 2.2 Teoria dos estágios da imagem da destinação (Gunn, 1972, p. 120).

Pela teoria dos estágios, a imagem que os visitantes em potencial, não-visitantes e visitantes que retornam a uma destinação possuem dela é diferente. Diversos estudos sustentam essa idéia, afirmando que a imagem que os visitantes que retornam ao local possuem tende a ser mais realista, complexa e diferenciada (Pearce, 1982, 1988; Chon, 1990, 1992). 
Porém, outros estudos afirmam que, com o passar do tempo, a imagem que o turista tem de uma destinação pode mudar (Phelps, 1986; Narayana, 1976) e tende a voltar a ser estereotipado, com descrições semelhantes do lugar, geralmente iguais às vendidas em folhetos promocionais (Jenkins, 1993, p. 81).

Para melhor compreensão da formação da imagem, vamos dividi-la em duas partes. A primeira, que será chamada de "componentes de imagem", tem relação com a formação orgânica de Gunn (1972) e os fatores de demanda de Stabler (1988) na medida que é uma análise de como a imagem da destinação é percebida pelos turistas. A segunda parte será chamada de "determinantes de imagem" e corresponde à formação induzida da imagem, seguindo os conceitos de Gunn (1972) e os fatores de oferta segundo Stabler (1988). Ou seja, é uma análise de como os planejadores do turismo podem influenciar na formação da imagem. Portanto, entender os "componentes de imagem" leva os planejadores a agirem nos "determinantes de imagem" para melhorar a percepção do turista em relação à determinada destinação. Cabe lembrar que a imagem formada não é estática. Ela muda conforme o tempo e os eventos vão acontecendo. Por isso, a imagem de uma destinação deve ser constantemente monitorada e analisada.

\section{3 - Componentes de Imagem}

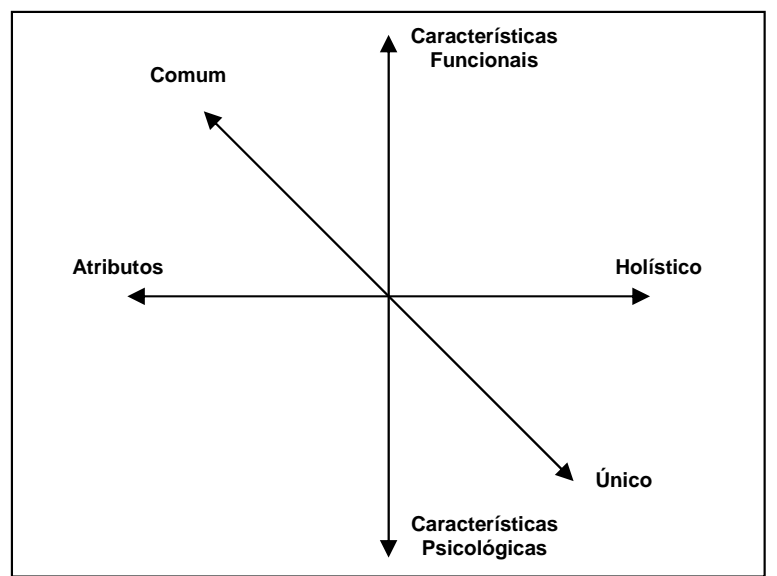

Figura 2.3 Componentes da imagem de destinações (Echtner e Ritchie, 1991). 
Como já foi citado anteriormente, componentes de imagem relacionam-se à análise da percepção que o turista tem da destinação.

Mayo (1975), investigando as imagens que turistas regionais tinham dos National Parks na América do Norte descobriu 3 componentes ou dimensões básicas: cenário, congestionamento e clima. Como a maioria dos autores, Mayo foca suas dimensões nos aspecto físico/funcional da destinação que são observadas diretamente e facilmente mensuráveis como preço e temperatura do local.

Poucos são os estudos que se preocupam com os aspectos menos tangíveis e conseqüentemente difíceis de serem medidos da destinação, que são as características psicológicas, como a atmosfera ou uma ambientação romântica. Ross (2001, p. 78) comenta que a única variável psicológica medida na maioria dos estudos é a receptividade ou hospitalidade do povo local.

A análise dos aspectos psicológicos foi um dos méritos de Echtner e Ritchie (1991). Além disso, o componente comum/único é outra grande variável que difere o trabalho deles, já que foi negligenciado na maior parte dos estudos sobre imagem, mesmo sendo simples perceber que algumas características das destinações são comuns entre elas e outras são únicas, próprias, como será exemplificado posteriormente.

Echtner e Ritchie (1991) identificaram três dimensões básicas da imagem de destinações:

- Atributos-Holístico: Atributos estão relacionados às características específicas de uma destinação. Holístico relaciona-se à impressão total, geral que o turista tem a seu respeito. Ambos podem variar desde o âmbito funcional até o psicológico.

- Funcional-Psicológico: A discussão sobre essa dimensão gira em torno de características e impressões tangíveis (ex: atrativos turísticos, acomodações, etc.) e abstratas (ex: hospitalidade, tranqüilidade, sentimentos religiosos, etc.). Elas podem ser comuns ou únicas. 
- Comum-Único: A terceira dimensão exposta relaciona-se a impressões e características que são freqüentemente encontradas e aquelas que são peculiares a algumas destinações.

O cruzamento dessas dimensões é que geram a imagem percebida da destinação. Por exemplo, atributos funcionais comuns são aqueles de fácil comparação entre as destinações, como preço, temperatura, tipos de acomodação. Atributos funcionais únicos são os símbolos e eventos especiais que fazem parte da destinação, como o Cristo Redentor no Rio de Janeiro e o Festival de Parintins no Amazonas. Já os atributos psicológicos comuns consistem na hospitalidade da população local, na notoriedade ou beleza de uma paisagem, enquanto os atributos psicológicos únicos incluem os sentimentos associados à peregrinação religiosa, como a visitação da Basílica de Aparecida do Norte ou lugares associados a eventos históricos, como Ouro Preto e Tiradentes em Minas Gerais.

Outro grande problema em pesquisar a imagem de destinações turísticas é que elas são representações "holísticas", ou seja, gerais, de um lugar. Na tentativa de entender a sua formação, muitos autores analisam apenas as partes ou atributos singulares e não o todo. Daí surge o questionamento: como analisar a aura ou atmosfera do lugar, já que estas não podem ser divididas em partes? Mais uma vez, Echtner e Ritchie (1991) solucionaram a questão incluindo a dimensão atributoholístico em seu modelo. Se de um lado existem os atributos funcionais e psicológicos, de outro há a imagem funcional e psicológica holística da destinação turística, que engloba as impressões gerais, a atmosfera, o humor do lugar.

A partir da análise da percepção da imagem da destinação, conseguida por meio da aplicação do modelo de Echtner e Ritchie (1991), parte-se para a determinação da imagem. 


\begin{tabular}{|c|c|c|c|}
\hline \multicolumn{2}{|c|}{$\begin{array}{l}\text { Conduta social da empresa } \\
\text {. Meio ambiente I Qualidade de vida } \\
\text {. Cidadania } \\
\text {. Comunidades }\end{array}$} & \multicolumn{2}{|c|}{$\begin{array}{l}\text { Conduta da empresa em relação aos empregados } \\
\text {. Respeito } \\
\text {. Salário } \\
\text {. Avanço pessoal }\end{array}$} \\
\hline \multirow{2}{*}{$\begin{array}{l}\text { Conduta de negócios da } \\
\text { empresa } \\
\text {. Reputação } \\
\text {. Inovação } \\
\text { - Segurança financeira } \\
\text {. Qualidade gerencial }\end{array}$} & & & $\begin{array}{l}\text { Conduta de contribuições sociais } \\
\text {. Caridade } \\
\text {. Escolas e universidades } \\
\text {. Organizações de arte }\end{array}$ \\
\hline & & & \multirow[b]{2}{*}{$\begin{array}{l}\text { Produto } \\
\text {. Características } \\
\text {. Desempenho } \\
\text {. Conformidade } \\
\text {. Durabilidade } \\
\text {. Qualidade } \\
\text {. Confiabilidade } \\
\text {. Reparabilidade } \\
\text {. Estilo }\end{array}$} \\
\hline $\begin{array}{l}\text { Força de vendas } \\
\text {. Tamanho e cobertura } \\
\text {. Competência } \\
\text {. Cortesia } \\
\text {. Confiabilidade } \\
\text {. Reação ( responsiveness) }\end{array}$ & & |AGEM & \\
\hline $\begin{array}{l}\text { Distribuição } \\
\text {. Locais } \\
\text {. ServiçolAss. técnica } \\
\text {. Competência }\end{array}$ & & & \multirow{2}{*}{$\begin{array}{l}\text { Comunicações } \\
\text {. Propaganda } \\
\text {. Publicity } \\
\text {. Promoções } \\
\text {. CRM/Mktg direto } \\
\text {. Telemktg/SAC }\end{array}$} \\
\hline \multirow{2}{*}{$\begin{array}{l}\text { Material de apoio } \\
\text {. Educacional } \\
\text {. Manuais } \\
\text {. Treinamento de } \\
\text { consumidores } \\
\text {. Consultas }\end{array}$} & \multirow{2}{*}{\multicolumn{2}{|c|}{$\begin{array}{l}\text { Assistência técnica } \\
\text {. Instalações } \\
\text {. Qualidade e tempo de reparos } \\
\text {. Disponibilidade de peças de reposição }\end{array}$}} & \\
\hline & & & $\begin{array}{l}\text { Preço } \\
\text {. Lista de preços } \\
\text {. Descontos de volume } \\
\text {. Descontos } \\
\text {. Condições financeiras }\end{array}$ \\
\hline
\end{tabular}

Figura 2.4 Determinantes de imagem (adaptado de Keller, 2000).

Feita a análise da percepção da imagem de uma destinação por parte do turista, é preciso compreender quais fatores a determinam. O que pode ser modificado ou monitorado para que se obtenha ou mantenha uma imagem positiva do local? Keller (2000), em seu livro Strategic Brand Management, cita onze determinantes de imagem de uma marca. Esses fatores, originalmente voltados para empresas, podem ser adaptados a destinações.

- Conduta social da empresa:

Pode ser entendido como a conduta social do país em relação ao meio-ambiente e o seu comprometimento com a melhoria da qualidade de vida no mundo, principalmente nos países mais pobres. 
- Conduta da empresa em relação aos empregados:

Pode ser entendido como a conduta de um país em relação aos seus habitantes: respeito, igualdade social, condições socioeconômicas, possibilidade de ascensão social. Os países nórdicos são exemplos de países voltados para o bem-estar de sua população (welfare state) e o Canadá, por exemplo, é reconhecido pelo seu alto índice de desenvolvimento humano (IDH).

- Conduta de negócios da empresa:

Pode ser entendido como a conduta polítco-econômica do país: como e por quem ele está sendo governado, sua reputação, segurança financeira, etc... Países como governantes corruptos (como o Brasil), em dificuldades para honrar seus compromissos financeiros (como a Argentina) ou instáveis politicamente (como a Venezuela) têm sua imagem afetada.

- Conduta de contribuições sociais:

Postura do país em relação à caridade, escolas, bibliotecas e universidades e organizações artísticas e culturais. A Europa, berço da civilização, é reconhecida por conservar seu patrimônio histórico cultural.

- Produto:

Quais produtos turísticos são ofertados pela destinação? Qual a qualidade oferecida por eles? Eles são adequados ao seu público-alvo?

- Preço:

Qual a política e o posicionamento de preço da destinação? São produtos caros ou populares? 
- Distribuição:

Onde o produto turístico é vendido? Por quem ele é distribuído?

- Força de Vendas:

Por quem o produto turístico é vendido e de que forma? Qual a política de vendas da destinação?

- Promoção (ou comunicações):

Quais ferramentas são utilizadas na comunicação da destinação (propaganda, publicidade, marketing direto, assessoria de imprensa) e de que forma?

- Material de apoio:

Pode ser entendido como o treinamento dado aos profissionais da área de turismo da destinação.

- Assistência técnica:

Pode ser entendido como a disponibilização de informação ao turista. Como é a sinalização ao turista? Quando ele tem algum problema durante sua viagem é fácil resolvê-lo?

Estando-se atento a esses onze fatores consegue-se monitorar a imagem que está sendo transmitida ou induzida ao consumidor.

\section{5 - Mensuração da imagem de destinações}

Jenkins (1999) fez uma análise sobre as principais técnicas de mensuração da imagem. 
Segundo Echtner e Ritchie (1991), a falha da maioria dos estudos que voltados à compreensão dos componentes da imagem da destinação relaciona-se ao método utilizado. A maioria utiliza métodos estruturados focados no componente atributo e não no componente holístico.

A utilização de métodos estruturados, tais como Likert e escalas de diferencial semântico, exige que o entrevistado classifique subjetivamente um grupo de atributos pré-determinados ou caracterize de maneira estimulada, utilizando as escalas padrões de classificação. Avaliações médias, escalas multidimensionais ou análise de fator são utilizadas para reduzir as contagens semânticas a um número menor de dimensões fundamentais percebidas. Por esse tipo de procedimento envolver uma lista prévia de atributos a qual um indivíduo deve analisar, ele tende a ser relativamente não-confiável (Timmermans et al., 1982, p. 191). A menos que a compilação dessa lista de atributos seja cuidadosamente feita, muitos desses atributos podem não ter importância para o indivíduo ou atributos relevantes podem ser esquecidos. As vantagens e desvantagens dos métodos estruturados e nãoestruturados são comparadas na tabela abaixo. 


\begin{tabular}{|c|c|c|}
\hline & Estruturado & Não - estruturado \\
\hline Descrição & $\begin{array}{l}\text { Vários atributos comuns de imagem são } \\
\text { especificados e incorporados em um } \\
\text { documento padrão e os entrevistados } \\
\text { classificam cada destinação em cada } \\
\text { um dos atributos, resultando em um } \\
\text { perfil de imagem. }\end{array}$ & $\begin{array}{l}\text { O entrevistado pode descrever } \\
\text { livremente suas impressões sobre uma } \\
\text { destinação. Os dados são recolhidos de } \\
\text { um número de entrevistados. Técnicas } \\
\text { de classificação e combinações são } \\
\text { usada, então, para determinar as } \\
\text { dimensões da imagem. }\end{array}$ \\
\hline Técnicas & $\begin{array}{l}\text { Geralmente um conjunto de escalas de } \\
\text { diferencial semântico ou Likert. }\end{array}$ & $\begin{array}{l}\text { Focus group, questionários abertos, } \\
\text { análises de conteúdo, entrelaçamento } \\
\text { de repertório. }\end{array}$ \\
\hline Vantagens & $\begin{array}{l}\text { - Facilidade de admnistração; } \\
\text { - Simplicidade na codificação; } \\
\text { - Facilidade de análise dos resultados } \\
\text { utilizando métodos estatísticos; } \\
\text { - Facilidade na comparação entre as } \\
\text { destinações. }\end{array}$ & $\begin{array}{l}\text { - Leva à mensuração dos componentes } \\
\text { holísticos da imagem da destinação; } \\
\text { - Redução da indução/influência do } \\
\text { entrevistador; } \\
\text { - Redução da possibilidade de perdas } \\
\text { importantes dos componentes ou } \\
\text { dimensões da imagem. }\end{array}$ \\
\hline Desvantagens & $\begin{array}{l}\text { - Não incorpora os aspectos holísticos } \\
\text { da imagem; } \\
\text { - Foco no atributo - forçando o } \\
\text { entrevistado a pensar na imagem do } \\
\text { produto em termos dos atributos } \\
\text { especificados; } \\
\text { - A qualidade de métodos estruturados } \\
\text { e a possibilidade de uma análise } \\
\text { completa por meio deles é variável - é } \\
\text { possível perder componentes. }\end{array}$ & $\begin{array}{l}\text {-Nível de detalhamento fornecido pelos } \\
\text { entrevistados é muito variável; } \\
\text { - Análises estatísticas dos resultados } \\
\text { são limitadas; } \\
\text { - Análises comparativas não são fáceis. }\end{array}$ \\
\hline
\end{tabular}

Figura 2.5 Métodos utilizados na pesquisa de imagem das destinações: Estruturados x Nãoestruturados (Jenkins, 1999).

A predominância de técnicas estruturadas na pesquisa de imagem, em especial aquelas relativas a escalas baseadas em palavras, também contribuiu para a concentração de técnicas verbais em relação a visuais nessas pesquisas. Pearce e Black (1996, p. 419) afirmam que os pesquisadores do turismo têm de "incorporar ainda o domínio visual no arsenal metodológico de suas próprias práticas de pesquisa e que, como acadêmicos, a familiaridade com os textos e as palavras influencia-nos a usar esta forma de apresentação em nossos estudos; uma prática que pode estar fora de moda com as experiências de um número crescente de visitantes cujo mundo é dominado cada vez mais por imagens visuais". Os 
pesquisadores devem começar a pensar criativamente na utilização de mapas e fotos para ajudar na lembrança do visitante e gerar dados mais ricos (Pearce e Black, 1996, p. 420). Pearce cita Craik (1971), que escreveu que a determinação dos meios da representação (que é como um ambiente deve ser apresentado aos entrevistados) é uma das considerações metodológicas críticas no estudo dos povos e do seu ambiente. Muitos estudos no campo da percepção ambiental usaram meios fotográficos. Seguindo uma meta-análise (que cobriu 11 estudos relevantes precedentes, 152 ambientes avaliados por 2400 entrevistados), Stamps (1990) encontrou uma correlação de 0.86 entre as preferências obtidas in situ e as preferências obtidas por meio das fotografias. Estes resultados tendem a apoiar o uso de estímulos fotográficos, mas poucos estudos de imagem assim o fizeram.

Poucos estudos publicados usaram consumidores para obter as construções ou atributos usados na investigação da imagem do destino. Pesquisas futuras devem combinar as duas técnicas (estruturadas e não-estruturadas) para conseguir resultados válidos. Isto envolve um esforço considerável nos estágios do projeto, utilizando técnicas não estruturadas para obter os atributos e dimensões relevantes da imagem da destinação para, então, utilizá-los de maneira estruturada na investigação das imagens. A Figura 2.6 esboça um modelo amplo para a condução da pesquisa de imagem de um local que incorpora duas fases da pesquisa. A primeira é uma fase qualitativa usando métodos não-estruturados para descobrir as construções relevantes ao grupo que está sendo estudado. A segunda fase pega os resultados obtidos na primeira e mede a imagem quantitativamente. As duas fases são discutidas mais detalhadamente abaixo. 
Fase Qualitativa

Propósito: Encontrar os conceitos usados pela população estudada no seu conhecimento da imagem da destinação.

Métodos: Construção de técnicas para descobertas como entrevistas, análises de conteúdo, triad elicitation e photo elicitation.

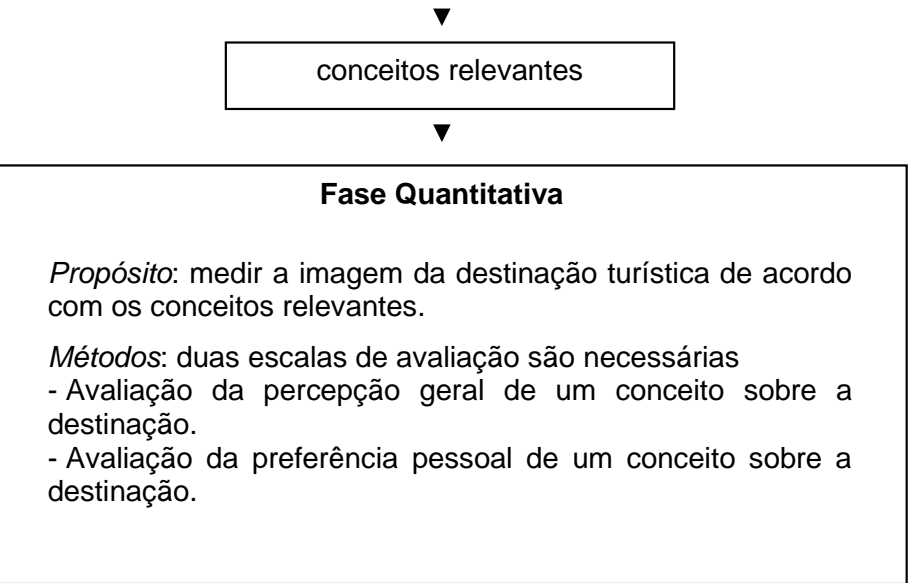

Figura 2.6 Um modelo para a pesquisa de imagem das destinações (Jenkins , 1999).

\subsection{1 - A fase qualitativa: a descoberta das construções}

A aplicação da pesquisa qualitativa na população estuda minimiza os riscos de obrigar ou influenciar os entrevistados a responderem a um sistema padrão que pode não ser a representação precisa da imagem que eles têm da destinação. Jenkins (1999) apurou que até o começo da década de 90, poucos foram os estudos que utilizaram a pesquisa qualitativa na descoberta de atributos, construções ou dimensões utilizadas na mensuração da imagem. Um dos primeiros trabalhos a adotar a descoberta das construções foi realizado por Crompton (1979) que utilizou a análise de conteúdo de materiais de leitura, folhetos de viagem e entrevistas nãoestruturadas com 36 estudantes para determinar os atributos a serem utilizados na pesquisa de percepção de estudantes americanos sobre o México. 
2.5.2 - A fase quantitativa: mensuração da imagem

Encontradas as construções, parâmetros ou atributos conhecidos e percebidos pelo grupo de turistas estudado, é possível utilizar métodos mais estruturados para medir diretamente a imagem que os indivíduos possuem da destinação. Essa mensuração pode envolver o pedido para que os turistas classifiquem certas destinações de acordo com os atributos filtrados anteriormente. A maioria dos estudos tem utilizado as técnicas de Likert ou de diferencial semântico com cinco ou sete pontos.

É importante ressaltar que duas escalas de avaliação são necessárias:

Primeiramente, o entrevistado avalia a destinação de acordo com uma construção específica, como 'Classifique o Rio de Janeiro em termos de beleza natural numa escala em que 1 é "nada bela" e 7 é "muito bela" '. Essa avaliação é chamada de percepção geral.

Depois, o entrevistado deve responder o grau de importância que a construção específica tem pêra ele pessoalmente, como ' O quanto à beleza natural é importante na sua decisão de viagem? Por favor, classifique na seguinte escala em que 1 é "Nada importante" e 7 é "Muito importante". Essa segunda avaliação é chamada de preferência pessoal.

A combinação das duas escalas de avaliação permite que o pesquisador entenda a imagem de uma destinação percebida pelos turistas. Também permite saber quais são os atributos mais relevantes para cada tipo de turista ou grupo de turistas. A preferência pessoal permite também a filtragem de segmentos de mercado de acordo com os interesses de viagem. A imagem "estereotipada" de um lugar pode ser comparada à imagem de outro dentro de um mesmo segmento de mercado. A mensuração da imagem utilizando essa técnica também permite o pesquisador observar as mudanças da imagem com o passar do tempo devido a experiências de viagem. 


\section{3 - A IMAGEM DO BRASIL NO EXTERIOR}

Não são muitos os estudos que analisam a imagem do Brasil no exterior. A Embratur iniciou em outubro de 2003 um estudo de como a imprensa estrangeira explora a imagem do Brasil e qual o conhecimento que os principais jornalistas e formadores de opinião de outras nacionalidades têm sobre o país a ser realizado em 10 países. Havia mais de 10 anos que a Embratur não realizava estudos sobre a imagem do país no exterior e os diagnósticos servirão para nortear as ações de promoção do Brasil como destino turístico. Porém, esse estudo não foi concluído antes do término desse trabalho.

Por isso, para a identificação da imagem do Brasil no exterior, foram utilizados dois estudos: o da Confederação Nacional do Transporte (CNT) de 2001, analisado pr Flávio de Faria Alvim (2002) e o da Universidade de Purdue nos EUA, realizado em 2002 por Aline Rezende Parker, Alastair Morrison e Joseph Ismail, analisado pela própria Parker (2003).

A metodologia utilizada foi de análise comparativa entre as duas pesquisas e as duas análises, observando os pontos de convergência e as diferenças entre ambas.

\section{1 - Confederação Nacional do Transporte}

Turismo no Brasil

13/10/2002

Flávio de Faria Alvim

A Confederação Nacional do Transporte (CNT) encomendou, pela primeira vez, em 2001, uma pesquisa mundial para saber como o mundo vê o Brasil. A pesquisa foi realizada em 22 países entre eles os Estados Unidos, Japão, Inglaterra e África do Sul e foi coordenada pelo Instituto Sensus, com apoio da Universidade de Michigan, nos EUA.

O Brasil e seu povo continuam sendo conhecidos no mundo por suas praias, futebol, alegria e cordialidade e seus produtos de exportação mais conhecidos ainda são o café e a banana. Para $58,2 \%$ dos entrevistados, o café é o principal produto de 
exportação quando, na verdade, o café só representa $3 \%$ da pauta brasileira de exportações.

A imagem mais associada ao país é o futebol apontado por $36,6 \%$ dos entrevistados e o carnaval por $19,4 \%$ dos ouvidos. $75 \%$ dos entrevistados souberam dizer que o Brasil se encontra na América do Sul e aqueles que indicaram vontade de conhecer o Brasil se sentem motivados pelo sol, praias e a natureza brasileira.

O brasileiro mais ilustre no exterior ainda é o eterno rei Pelé, seguido do jogador Ronaldinho fenômeno e do falecido piloto Ayrton Senna.

Um dado para refletir é que $70,4 \%$ dos entrevistados disseram que o mundo deveria contribuir para a preservação da floresta amazônica por meio de organismos internacionais. Alvim (2002) analisa este dado com dois enfoques: pode ser uma boa oportunidade para captação de recursos ou significa que boa parte do mundo acredita que o Brasil não tem condições de preservar a maior floresta tropical do mundo, tornando-se uma questão de soberania nacional.

O brasileiro é visto como um povo alegre, hospitaleiro, confiável e trabalhador por quase todos os países do mundo. Por isso, Alvim (2002) acredita que os brasileiros devem conhecer melhor o seu próprio país para ajudar a vender sua imagem. A mais eficiente propaganda é a boca-a-boca. Nos Estados Unidos o turismo interno é maior que todo o movimento turístico internacional. Antes de multiplicar o fluxo turístico internacional para o Brasil é necessário garantir a multiplicação deste turismo interno com a certeza de que os turistas brasileiros estejam encantados com o turismo em seu país. O turismo no Brasil precisa ser melhor, mais barato e de melhor qualidade do que o encontrado em outros países. Aí sim, será possível utilizar o turismo planejado como um grande captador de divisas para o Brasil.

\section{2 - Purdue University}

Estudo Exploratório da Imagem do Brasil como Destino Turístico na Visão de Norte Americanos Interessados em Viagens \& Turismo

25/10/2003 
Aline Rezende-Parker

"Apesar de sua imponente extensão territorial, crescente importância econômica no cenário mundial e incontáveis atrações turísticas, o Brasil ainda não é bem conhecido pelos norte-americanos. Sua proximidade a países hispânicos na América do Sul e a crescente popularização da música e cultura latina nos Estados Unidos que muito pouco refletem a cultura brasileira, ajudam, ainda mais, a confundir a imagem que os norte-americanos têm do Brasil". Essa é a principal conclusão de Parker (2003).

Para a indústria brasileira do turismo, é essencial que se entenda como os norteamericanos vêem nosso país em termos de destino turístico. Afinal, eles são os que mais gastam enquanto visitam o país e estão entre os que permanecem por mais tempo (11,8 dias em média) representando um importante e promissor mercado consumidor do produto turístico brasileiro. (Embratur, 2001).

Portanto, os três objetivos principais deste estudo foram: (a) Determinar a imagem que norte-americanos interessados em viagens e turismo têm do Brasil como um destino turístico; (b) Determinar se estes norte-americanos conseguem diferenciar o Brasil de seus países vizinhos; (c) Identificar entre os entrevistados, grupos de norteamericanos que possuem imagens semelhantes do Brasil.

A técnica para análise de imagem adotada por Parker foi a de Echtner e Ritchie , a mesma citada nesse trabalho (vide p.42) que criaram um modelo tridimensional para representar a imagem de um destino. Apenas para situar o leitor, vamos retomar os conceitos: por esse modelo, a imagem tem dois componentes: o componente de atributos e o componente holístico. Cada componente possui itens que podem ter características funcionais ou psicológicos e cada característica pode ser classificada como comum ou singular.

Para medir todos as dimensões da imagem e alcançar os objetivos da pesquisa, utilizou-se um questionário com três perguntas abertas e uma tabela onde os entrevistados mediram trinta e nove atributos do Brasil de acordo com uma escala de cinco opções: "Concordo Fortemente (5)", "Concordo (4)", "Neutro (3)", "Discordo 
(2)" e "Discordo Fortemente (1)". Para cada pergunta aberta, mais de uma resposta foi permitida e computada. As perguntas abertas ajudaram a medir os componentes holísticos, psicológicos e singulares da imagem, enquanto a tabela de atributos ajudou a medir os componentes de atributo, funcionais e comuns.

Para a primeira pergunta (Que imagens vêm a sua mente quanto você pensa no Brasil como um lugar para passar férias?), as duas principais respostas foram: belas praias $(42,1 \%)$ e a floresta amazônica $(40,8)$. Para a segunda pergunta (Que tipo de atmosfera ou "clima" você esperaria encontrar no Brasil?), as três principais respostas foram: clima de festa e celebração (27\%), amigável $(22,3 \%)$ e relaxante $(22,3 \%)$. Finalmente para e terceira pergunta (Cite algumas atrações exclusivas que você sabe que o Brasil possui), as principais respostas foram: Floresta e Rio Amazonas (57,5\%) e Rio de Janeiro (31,3\%). Até agora, estas são as duas atrações (juntamente com Foz do Iguaçu) que têm sido intensamente promovidas pela maioria dos mais importantes operadores de viagem norte-americanos. No entanto, estas atrações possuem imagens contrastantes que atraem públicos com perfis e interesses diferentes.

Imagens positivas foram encontradas para nove atributos: Muitos lugares interessantes para visitar $(4,3 \%)$, muitos parques naturais e vida selvagem $(4,3 \%)$, bom lugar para se ir a praia $(4,3 \%)$, variedade de música e dança $(4,4 \%)$, beleza natural $(4,5 \%)$, pessoas simpáticas $(4,1 \%)$, boa vida noturna (4.3\%), aventura (4\%), várias oportunidades de aumentar meu conhecimento sobre outra cultura $(4,35 \%)$.

Em termos de imagem negativa, a tabela de atributos e as perguntas abertas indicaram que os entrevistados não tinham uma boa percepção das condições econômicas e sociais no Brasil e que eles demonstravam uma certa preocupação com segurança enquanto visitassem ao país. Os atributos com imagens negativas confirmadas pelos entrevistados foram, segurança do sistema de transporte público (2,9\%), padrão de limpeza e higiene (2,8\%), mendigos (2,5\%), e barreiras de comunicação (2,9\%). Palavras como crime, violência, pobreza, perigo e medo foram usadas por, aproximadamente, $10 \%$ dos entrevistados para expressar 0 ambiente/atmosfera que eles esperavam encontrar no Brasil. Por isso, é muito importante que o Brasil preste atenção a estas preocupações para melhorar a 
imagem de visitantes atuais e potenciais e se tornar mais competitivo no mercado internacional do turismo.

A tabela de atributos também apresentou três afirmativas que comparavam o Brasil a seus países vizinhos em termos culturais e artísticos. Os resultados ficaram muito próximos ao ponto neutro da escala indicando que os entrevistados não foram capazes de, claramente, identificar as diferenças. As afirmativas foram: "Música e dança brasileiras são similares à música e dança de outros países da América do Sul e Central" (3,2\%), "A comida é picante e parecida com a comida Mexicana" $(3,5 \%)$, A cultura e os costumes dos brasileiros são bastante semelhantes à cultura e costumes de seus países vizinhos" (3,4\%). Esses resultados podem ser devido à falta de conhecimento da cultura brasileira entre a maioria dos respondentes. Outra explicação seria o contato com imagens erradas e confusas recebidas através da mídia e meios de informação. No entanto, quando se observou as respostas dos entrevistados que já estiveram no Brasil, percebeu-se que esses estavam mais seguros destas diferenças, principalmente no que se referiu à comida brasileira.

O terceiro objetivo foi agrupar os entrevistados de acordo com as imagens que possuíam do Brasil e assim formar grupos de pessoas com imagens semelhantes. Para tanto, utilizou-se as técnicas estatísticas de análise de fatores e cluster análises. Na primeira fase, agrupou-se todos os atributos em oito grupos ou fatores sendo eles:

1. Atrações naturais/Interesse

2. Segurança e Conforto

3. Comparações culturais

4. Infra-estrutura e informação

5. Clima de férias/exotismo

6. Condições econômicas e sociais

7. Transporte

8. Aventura/Aprendizado

Numa segunda fase, os respondentes foram agrupados de acordo com as imagens que possuíam de cada um dos fatores estabelecidos. O resultado desta análise 
revelou quatro grupos diferentes. O grupo 1 caracterizou-se por possuir uma imagem geral positiva do Brasil. Este grupo possuía imagens positivas de todos os fatores com exceção dos fatores Transporte e Condições Sociais. O grupo 1 foi também o que mais claramente soube diferenciar o Brasil dos seus países vizinhos e, o mais interessante, é que possuía o maior número de respondentes que já haviam visitado o Brasil (65\%).

Os grupos 2 e 3 três foram grupos intermediários que tiveram imagens neutras do Brasil para a maioria dos fatores. O grupo dois em particular era formado na sua maioria por respondentes que nunca haviam visitado o Brasil (72\%). Por fim, o grupo 4 caracterizou-se por possuir mais imagens neutras e negativas do Brasil do que todos os outros grupos. Este grupo possui o maior percentual de respondentes que nunca visitaram o Brasil $(86,8 \%)$.

Enquanto esta pesquisa revela implicações para o marketing do turismo brasileiro, existem outras implicações para o turismo de destinos em geral. A primeira delas é que turistas que visitam um lugar, não apenas são os que têm a imagem mais positiva daquele lugar, como também têm o mais acurado entendimento das limitações do destino turístico (como, por exemplo, o transporte no Brasil para o grupo 1). Testemunhos e outras formas de endosso por parte destes visitantes são uma boa maneira de esclarecer a potenciais visitantes como realmente um lugar turístico é, e desta forma aliviar a apreensão ou medo entre eles.

A segunda implicação surge do descobrimento que os norte-americanos são geralmente incapazes de, claramente, diferenciar o Brasil de países vizinhos de fala espanhola. Isto pode indicar uma tendência geral das pessoas assumirem que lugares vizinhos são semelhantes, a não ser que eles tenham informações específicas que provem o contrário. Por tanto, é de responsabilidade dos administradores de marketing desenvolver imagens e estratégias de comunicação que claramente diferenciem seus destinos de áreas vizinhas, bem como de seus principais competidores.

Outra implicação é o dilema criado pelo descobrimento das duas principais imagens do Brasil como um destino turístico (belas praias e floresta Amazônica). Deveriam as 
estratégias de marketing ser diferentes para pessoas com diferentes imagens do país? Alternativamente, deveria ser usada uma abordagem do tipo "tamanho único" em que a mesma imagem é comunicada a todos os visitantes?

A grande e atual tendência das estratégias de marca parecem sugerir que a segunda estratégia é a mais indicada. Tentar promover duas imagens diferentes para uma audiência geral, como turistas americanos, pode ser confuso e ineficiente. Se é difícil ter uma imagem clara e categorizada de um destino turístico na mente dos viajantes como é o caso do Brasil, então é muito provável que este país nem entre na lista de escolha dos turistas. Em outras palavras, se o Brasil não tem uma imagem forte, (ex. As Bahamas e Cancun como lugares de praia, África como aventura ou Europa como história e cultura) provavelmente não será uma das opções.

Esta imagem forte ainda não foi eficientemente estabelecida no mercado americano e investimentos adicionais para desenvolvê-la são necessários. Além disso, mais esforços são necessários para mudar e melhorar os aspectos negativos da imagem que o Brasil tem nos Estados Unidos. Por exemplo, atenção especial deveria ser dada a turistas como os do Grupo 1 que apresentaram ter uma imagem negativa do transporte e condições econômicas e sociais. Uma vez que este grupo é composto na sua maioria de turistas que já visitaram o Brasil, a percepção destes entrevistados é baseada em uma experiência real e indica um ponto fraco do produto turístico brasileiro que precisa ser desenvolvido pelas autoridades brasileiras de turismo.

É preciso ser dito que este estudo foi de natureza exploratória e que os resultados precisam ser confirmados por outras pesquisas mais amplas com amostras compostas por um maior numero de americanos de mais diversos backgrounds e não somente aqueles interessados em viagens e turismo. É também importante reconhecer que a taxa de respostas da pesquisa (realizada on-line) foi baixa apesar de ter sido grande o suficiente para que as técnicas de analise estatística fossem aplicadas. Apesar destas limitações, este estudo contribuiu para validar a técnica de Echtner e Richie de medir a imagem de destinos turísticos. 


\section{Análises dos Dados}

Os dois estudos apresentados anteriormente, um com um público amplo de diversos países e outro restrito aos norte-americanos, chegam a conclusões muito parecidas. Os turistas potenciais do Brasil, em geral, não conhecem verdadeiramente o país.

Apesar da maioria dos entrevistados saberem que o Brasil localiza-se na América do Sul, poucos conseguem diferenciá-lo dos demais países latino-americanos. Nossa imagem ainda é associada ao futebol, praia, carnaval e natureza. Tanto que os brasileiros mais conhecidos no exterior são Pelé, Ronaldinho e Ayrton Senna. Nossas exportações mais conhecidas são o café e a banana.

Como pontos positivos, são citados a hospitalidade do brasileiro, a beleza natural, parques naturais e vida selvagem, aventura, praias, variedade de música e dança e boa vida noturna, que acaba sendo associada ao turismo sexual.

Como pontos negativos, as condições socioeconômicas e a segurança são os mais críticos.

Ficou claro que os turistas que visitaram o Brasil são os que possuem a melhor imagem do país, mas também os que mais conhecem seus problemas e limitações turísticas. Enquanto isso, turistas que nunca visitaram o Brasil possuem imagem negativa em relação a ele.

Em suma, pela aplicação da análise de componentes de Echtner e Ritchie, continuamos a ter a imagem de um país selvagem, de praia, carnaval e sexo fácil. Isso porque durante anos, cultuamos o hedonismo, acreditando que sol, floresta, praia, corpo e sexo representavam o melhor da vida e adotamos o "jeitinho brasileiro", endossado pela "Lei de Gérson" em que o importante seria levar vantagem em tudo. Por isso, a indústria turística brasileira continua pagando caro pelo engano de achar que o diferencial brasileiro era apenas a sua "esperteza", seus recursos naturais e a beleza de suas mulheres.

Até quando continuaremos a vender essa imagem? 
Tudo indica, pelo atual momento, que por pouco tempo. A criação do Ministério do Turismo e a determinação para a Embratur cuidar apenas da imagem do Brasil no exterior e da captação de turistas estrangeiros mostram esse novo foco.

Mas como mudar uma imagem que foi formada há tanto tempo? É aí que entra a parte dos determinantes de imagem.

O primeiro passo é a melhoria da qualidade de vida de nossa população. Mas não podemos esperar que isso ocorra da noite para o dia. Ao invés de apenas reclamarmos dos defeitos, devemos reconhecer as qualidades e os avanços que conseguimos até aqui. Como diz o professor Marins em suas palestras, “... quando o copo está na metade, podemos dizer que ele está meio cheio ou meio vazio". Vamos enxergar essa metade cheia. Dados relativos a 2001 colhidos no site da Anthropos Consulting, do professor Marins, indicam que o Brasil está entre as 10 maiores economias do mundo. Entre seus principais produtos de exportação estão aviões, automóveis, celulares, além de mineração, aço e produtos da agroindústria e pecuária. Temos o $10^{\circ}$ maior parque industrial do mundo. Somos o único país do hemisfério Sul a participar do projeto Genoma. Nosso programa de combate à AIDS é referência mundial. As condições sociais da população (educação, habitação e saneamento básico) evoluíram muito nos últimos anos. Precisamos mudar a imagem que temos de nós mesmos.

A imagem que se tem de um lugar depende do suporte de diversas fontes, tais como reportagens em jornais e revistas, documentários e folheteria específica. Porém, o que mais influencia esta imagem é o relato de amigos e parentes que tiveram a experiência da viagem. Disto resulta a falácia de se culpar a imprensa pela imagem negativa do Brasil, ao divulgar informações que contribuem para denegrir o país. Segundo Pires (2002), "a imprensa apenas reflete a imagem e anseios que nós temos do país. Afinal, ela não está nem além, nem aquém da sociedade em que atua, mas é parte integrante dela. Se em países como Espanha, França, Estados Unidos e mesmo a nossa vizinha Argentina sua imprensa divulga poucas notícias desabonadoras, isso ocorre porque certamente os leitores dos jornais e os telespectadores querem ver outro tipo de informação: eles mesmos, veículos, jornalistas, leitores, têm uma imagem positiva dos seus países, que acaba se 
refletindo no noticiário como um todo, transcendendo os aspectos negativos, que também existem".

O enfoque da promoção turística brasileira é que deve ser mudado. Campanhas que mascarem a realidade do país apenas contribuirão para o descrédito da imagem do Brasil.

Não adianta pensarmos numa mudança de imagem da noite para o dia. Ela tem que ser construída a médio ou longo prazo, começando com a consciência de que não temos apenas recursos naturais e mulheres bonitas. Temos também uma economia pujante, uma civilização hospitaleira e um legado histórico-cultural reconhecido mundialmente.

"Quando o brasileiro tiver uma melhor visão de seu país, seremos mais reconhecidos e apreciados no exterior" (Pires, 2002). 


\section{4 - CONCLUSÕES}

Analisando os modelos de comportamento do consumidor em turismo ilustrados no trabalho e adaptando-os, pode-se dizer que a estrutura básica formada seria:

- o surgimento da necessidade;

- o reconhecimento da necessidade - o estágio pré-requisito;

- nível de envolvimento - quantidade de tempo e esforço investida no processo de decisão, por exemplo, grau de busca de informação;

- identificação de alternativas - marcas que inicialmente vêm à mente quando se considera uma compra são consideradas como o conjunto evocado. Entretanto, amigos, vendedores, mercadorias, folhetos, anúncios, etc, podem proporcionar um estágio de avaliação;

- avaliação das alternativas - comparações são feitas sobre a percepção (imagem) e principais atributos, baseadas nos critérios do comprador potencial;

- decisão - escolha feita;

- ação de aquisição;

- comportamento pós-aquisição - os sentimentos de indivíduo posteriores à aquisição. Muitas vezes, no caso de aquisições importantes, como as de viagens ao exterior, aquele que faz a aquisição colocará em dúvida o acerto de sua escolha e considerará a necessidade de reconfirmação do que já sabe como sendo uma dissonância ou um desequilíbrio. Este estado psicológico é reduzido através de garantias ou linhas telefônicas de auxílio para lidar com os questionamentos. Ele também é reduzido pela recepção das pessoas em seu retorno da viagem ou experiência.

Nota-se que, a partir do modelo de Schmoll (1977), a imagem passou a ser considerada um dos principais fatores de influência na escolha da destinação turística.

A imagem pode ser estudada em dois estágios do comportamento de compra considerados cruciais: na identificação das alternativas (estágios iniciais do processo de escolha da destinação) e na avaliação das alternativas pré-decisão (estágio decisório). 
Afinal, para alguns autores, caso o consumidor não tenha na sua cabeça a imagem do lugar, ele não é nem cogitado para visitação. A imagem também é um dos grandes diferenciais no momento da tomada de decisão. Portanto, não há como negar a importância da imagem e a necessidade de seu estudo aprofundado.

Para um entendimento completo da imagem de uma destinação é necessária a análise de dois aspectos. Inicialmente, os componentes da imagem devem ser analisados. Essa parte pode ser chamada de diagnóstico. É aí que são aplicados o modelo de pesquisa de imagem de Jenkins (1999), dividido na fase qualitativa e na fase quantitativa e o de Echtner e Ritchie (1991), que analisa as dimensões da imagem. Nela descobre-se como a destinação é percebida pelos consumidores. A partir daí, obtêm-se os subsídios para a análise de outro aspecto: os determinantes de imagem. Nessa parte estão inclusos os esforços de marketing que uma destinação faz para atrair visitantes. Porém, como foi dito, a imagem não é feita apenas do ponto de vista do marketing, mas sim de todo um conjunto de componentes.

Por isso, afirma Pires (2002):

Quando falamos de imagem, portanto, havemos de reconhecer que não adianta uma mera divulgação por meio de uma boa campanha institucional, porque o fruto será inevitavelmente uma imagem artificial e postiça. Mudanças verdadeiras só ocorrerão quando mudarmos a imagem que temos de nós mesmos.

(Pires, 2002, p. 27)

Isso fica confirmado com as conclusões da análise de Alvim (2002) quando ele diz que a principal propaganda de uma destinação é a boca-a-boca. Portanto, a melhor propaganda do Brasil é feita pelo próprio brasileiro na medida em que ele conhece o seu país e fica encantado com suas destinações.

Para que mudemos a imagem que temos de nós mesmos, os pressupostos mais óbvios são reformas que contribuam para uma melhora da qualidade de vida geral da população (um dos determinantes de imagem). Outros, não tão visíveis assim, mas igualmente importantes, incluem o incremento do civismo, hoje quase 
completamente esquecido, e conseqüentemente do sentimento de pertencimento por parte do brasileiro. Precisamos descobrir a nós mesmos, valorizar os aspectos de nossa cultura e difundi-los.

Por isso, a conclusão deste trabalho é a mesma de Pires (2002) de que:

\begin{abstract}
Quando nós brasileiros tivermos uma melhor visão de nosso país, seremos, em decorrência, mais bem reconhecidos e apreciados no exterior. Esse aspecto, somado aos outros já abordados, provocará uma verdadeira revolução no turismo nacional, ressaltando sua importância de agente no moderno desenvolvimento econômico, papel que já cumpre em outros países que não colocaram o turismo, necessariamente, como prioridade. A mudança de imagem deve acontecer de dentro para fora, e aí sim, reconhecida, poderemos qualquer destinação no Brasil, pois ela terá novo apelo aos olhos do turista estrangeiro e até mesmo do turista brasileiro.
\end{abstract}

(Pires, 2002, p. 27)

Assim, identificada a imagem do Brasil no turismo e os fatores que levam à formação da mesma, é preciso agora a ação, a pró-atividade para que novos trabalhos sobre o assunto sejam realizados com um aprofundamento contínuo e, mais do que isso, que todos atores do setor turístico compreendam a importância de seu papel na construção de uma imagem mais positiva do país. Com este trabalho, o primeiro passo foi dado. 


\section{Referências Bibliográficas}

ALVIM, F. F. "Turismo no Brasil". 13 de outubro de 2002. (Disponível na Internet em: $<$ www.estudosturisticos.com.br>).

ASSAEL, H. Consumer Behavior and Marketing Acttion. Boston: Kent, 1984.

BIGNAMI, R. A imagem do Brasil no Turismo: Construção, desafios e vantagens competitivas. São Paulo: Aleph, 2002.

BONIFACE, B., COOPER, C. The Geography of Travel and Tourism. London: Heinemann, 1987.

$\mathrm{CHON}, \mathrm{K}$. S. "The role of destination image in tourism: a review and discussion. The Tourist Review, v. 2, p. 2-9, 1990.

$\mathrm{CHON}, \mathrm{K} . \mathrm{S}$. "The role of destination image in tourism: an extension. The Tourist Review, v. 2, p. 2-7, 1992.

COHEN, E. "Towards a sociology of international tourism",.Social Research, v. 39, n. 1, p.164-182, 1972.

COHEN, E. "Who is a tourist? A conceptual clarification". Sociological Review, v. 22, n. 4, p. 527-555, 1974.

COHEN, E. "The sociology of tourism, approaches, issues findings". Annual Review of Sociology, p. 373-392, 1984.

COOPER, Chris, FLETCHER, John, WANHILL, Stephen, GILBERT, David, SHEPHERD, R. Turismo, princípios e Prática. 2. ed. Porto Alegre: Bookman, 2001.

CRAIK, K. H., "The assessment of places, em McReynolds, P. (Editor)". Advances in Psychological Assessment: Science and Behaviour, Vol. 2. California: Palo Alto, p. 40-62, 1971.

CROMPTON, J. L., "An assessment of the image of Mexico as a vacation destination and the influence of geographical location upon that image". Journal of Travel Research, V. 17, n. 4, p. 18-23, 1979.

DANN, G. M. S. "Tourist Motivation: an appraisal". Annals of Tourism Research, v. 8, n. 2, p. 187-219, 1981.

ECHTNER, C., RITCHIE, J. B. "The Meaning and Measurement of Destination Image". Journal of Tourism Studies, v. 2, n. 2, p. 2-12, 1991.

ECHTNER, C., RITCHIE, J. B. "The measurement of Destination Image: An Empirical Assessment". Journal of Travel Research, v. 31, n. 4, p. 3-13, 1993. 
ENGEL, J. F., BLACKWELL, R. D., MINIARD, P. Consumer Bahavior. New York: Dryden Press, 1986.

GALLARZA, M. G., GARCíA, H. C, SAURA, I. G. "Destination Image Towards a Conceptual Framework". Annals of Tourism Research, v. 29, n. 1, p. 56-78, 2002.

GUNN, C. Vacationscape - Designing Tourist Regions. Austin: University of Texas Press, 1972.

HOWARD, J. A., SHETH, J. N. The Theory of Buyer Behavior. New York: Wiley, 1969.

HUNT, J. D. "Image as a factor in tourism development". Journal of Travel Research, v. 13, p. 1-7, 1975.

ISMAIL, J. A., MORRISON, A. M., PARKER, A. R. "Dazed and confused? An exploratory study of the image of Brazil as a travel destination". Journal of Vacation Marketing, v. 9, n. 3, p. 243-259, 2003.

JENKINS, O. H. Marketing and the ecotourism paradox. Sidney: University of Sidney Thesis, submitted in partial fulfillment of the Bachelor of Economic (Social Sciences), Department of Geography, 1993.

JENKINS, O. H. "Understanding and Measuring Tourist Destination Images". International Journal of Tourism Research, v. 1, n. 1, p. 1-15, 1999.

JENKINS, O. H., MCARTHUR, S. "Marketing Protected Areas". Australian Parks and Recreation, v. 32, n. 4, p. 10-15, 1996.

KELLER, K. L. Strategic Brand_Management. New York: Prentice Hall, 2000.

KOTLER, P. Administração de Marketing. 5. ed. São Paulo: Atlas, 1998.

LEAL, S. A relevância da imagem para o processo de escolha de destinações. Revista Eletrônica de Turismo. Campo Largo: Faculdade Cenecista Presidente Kennedy. V. 2, n. 2, nov. 2002. (Disponível na Internet em: $<w w w . p r e s i d e n t e k e n n e d y . b r / r e t u r / v o l u m e 2 / a r t i g o 01 . p d f>$ )

LAWSON, F., BAUD-BOVY, M. Tourism and Recreational Development. London: Architectural Press, 1977.

MCINTOSH, R. W., GOELDNER, C. R., RITCHIE, J. B., Tourism, Principles, Practices, Philosophies. New York: Wiley, 1995.

MASLOW, A. H. "A theory of human motivation". Psychological Review, v. 50, p. 370-396, 1943.

MATHIESON, A., WALL, G. Tourism: Economic Physical anda Social Impacts. London: Longman, 1982. 
MAYO, E. J. "Tourism an national parks: a psychographic and attitudinal study". Journal of Travel Research, v. 14, p. 14-18, 1975.

MAYO, E., JARVIS, L. The Psychology of Leisure Travel. Boston: CBI Publishing, 1981.

MINISTÉRIO DO TURISMO, "Plano Nacional do Turismo, Diretrizes Metas e Programas, 2003-2007". Brasília, 29 de abril de 2003.

MOSCARDO, G., MORRISON, A. M., PEARCE, P. L., LANG, C. T., O'LEARY, J. "Understanding vacation destination choice through travel motivation and activities". Journal of Vacation Marketing, v. 2, n. 2, p. 109-122, 1996.

NARAYANA, C. L. "The stability of perceptions". Journal of Advertising Research, v. 16, n. 2, p. 45-49, 1976.

NICOSIA, F. M. Consumer Decision Processes: Marketing and Advertising Implications. Englewood Cliffs: Prentice Hall, 1966.

NOLAN, D., "Tourist's use and evaluation of travel information". Journal of Travel Research, v.14, p. 6-8, 1976.

PARKER, A. R. "Estudo Exploratório da Imagem do Brasil como Destino Turístico na Visão de Norte-Americanos Interessados em Viagens \& Turismo". 25 de outubro de 2003. (Disponível na Internet em <www.estudosturisticos.com.br>).

PEARCE, P. L. "Perceived changes in holiday destinations". Annals of Tourism Research, v. 9, n. 2, p. 145-164, 1982.

PEARCE, P. L. The Ulysses Factor: Evaluating Visitors in Tourist Settings. New York: Springer-Verlag, 1988.

PEARCE, P. L., BLACK, N. "The simulation of tourist environments: methodological perspectives for enhancing tourism research", em Proceedings of the Australian Tourism and Hospitality Research Conference, Australian and International Perspectives. Coffs Harbour: Bureau of Tourism Research, 1996.

PHELPS, A. "Holiday destination image - the problem of assessment". Tourism Management, v. 7, n. 3, p. 168-180, 1986.

PIKE, S. "Destination image analysis - a review of 142 papers from 1972 to 2000". Tourism Management, v. 23, p. 541-549, 2002.

PIRES, M. J. Lazer e Turismo Cultural. São Paulo: Manole, 2001.

PIRES, M. J. "O Brasil se vê com distorção". O Estado de São Paulo, $1^{\circ}$ de julho de 1997.

RELATÓRIO MUNDIAL. CNT/Sensus, 2001. 
ROSS, G. F. Psicologia do Turismo. São Paulo: Contexto, 2001.

SANTANA, G. "Criminality, Safety and Tourism: The image of the Camboriú beach resort, Brazil, from the viewpoint of tourists and residents". Estudios y Perspectivas en Turismo, v. 10, p. 267-280, 2001.

SCHMOLL, G. A. Tourism Promotion. London: Tourism International Press, 1977.

SCOTT, D. R., SCHEWE, C., FREDERICK, D. "A multi-brand/multi-attribute model of tourist state state choice". Journal of Travel Research, v. 17, n. 3, p. 23-29, 1978.

$\mathrm{SHIH}, \mathrm{D}$. "VALS as a tool of tourism market research". Journal of Travel Research, Spring, p. 2-11, 1986.

STABLER, M. J. "The image of destination regions: theoretical and empirical aspects, em Goodall, B., Ashworth, G. (Editores). Marketing in the Tourism Industry - the Promotion of Destination Regions. London: Routledge, p. 133-159, 1988.

STAMPS III, A. E. "Use of photographs to simulate environments: a meta-analysis". Perceptual and Motor Skills, v. 71, p. 907-913, 1990.

TIMMERMANS, H., Van ER HEIJDEN, R. WESTERVELD, H. "The identification of factors influencing destination choice: an application of the Repertoty Grid methodology". Transportation, v. 11, p. 189-203, 1982.

UM, S., CROMPTON, J. "Attitude Determinants in Tourism Destination Choice". Annals of Tourism Research, v. 17, n. 3, p. 432-448, 1990.

WAHAB, S., CRAMPON, L. J., ROTHFIELD, L. M. Tourism Marketing. London: Tourism International Press, 1976.

WELLS, W., GUBAR, G. "Life cycle concepts in marketing research". Journal of Marketing Research, Nov., p. 355-363, 1966.

WOODSIDE, A. G., LYSONSKI, S. "A General Model of Traveler Destination

Choice". Journal of Travel Research, v. 27, n. 4, p. 8-14, 1989. 